NBER WORKING PAPER SERIES

\title{
FEAR AND THE SAFETY NET: EVIDENCE FROM SECURE COMMUNITIES
}

\author{
Marcella Alsan \\ Crystal Yang \\ Working Paper 24731 \\ http://www.nber.org/papers/w24731
NATIONAL BUREAU OF ECONOMIC RESEARCH
1050 Massachusetts Avenue \\ Cambridge, MA 02138 \\ June 2018, Revised July 2019
}

We thank seminar participants at UC Berkeley Haas, UC Berkeley Demography, UC Berkeley Law, University of Colorado Boulder, Stanford, UCSD, UCLA, UC Davis, University of British Columbia, UC Irvine, Pomona, Princeton, Harvard, University of Texas Austin, the American Law and Economics Association Annual Meeting, Junior Criminal Law Roundtable, NBER Summer Institute, Columbia, Northwestern, and NBER Law and Economics for many helpful comments and suggestions. Barbara Biasi, Adam Cox, Janet Currie, Manasi Deshpande, Will Dobbie, Mark Duggan, Amy Finkelstein, Josh Gottlieb, Hilary Hoynes, Kevin Johnson, Thomas Lemieux, Justin McCrary, Alison Morantz, Melanie Morten, Ted Miguel, Shayak Sarkar, Maya Rossin-Slater, Isaac Sorkin, Reed Walker, and Tara Watson provided early feedback that improved the work. Morgan Foy, Ashley Litwin, Regina Powers, Matthew Tarduno, and Anlu Xing provided excellent research assistance. We thank Sue Long of TRAC for assistance with data under our appointments as TRAC Fellows. The collection of PSID data used in this study was partly supported by the National Institutes of Health under grant numbers R01 HD069609 and R01 AG040213, and the National Science Foundation under award numbers SES 1157698 and 1623684. We thank the Stanford Institute for Economic Policy Research and Stanford Health Policy for funding. The views expressed herein are those of the authors and do not necessarily reflect the views of the National Bureau of Economic Research.

NBER working papers are circulated for discussion and comment purposes. They have not been peer-reviewed or been subject to the review by the NBER Board of Directors that accompanies official NBER publications.

(C) 2018 by Marcella Alsan and Crystal Yang. All rights reserved. Short sections of text, not to exceed two paragraphs, may be quoted without explicit permission provided that full credit, including $(\odot$ notice, is given to the source. 
Fear and the Safety Net: Evidence from Secure Communities

Marcella Alsan and Crystal Yang

NBER Working Paper No. 24731

June 2018, Revised July 2019

JEL No. I14,I3,K00,K37

\title{
ABSTRACT
}

This paper studies how changes in deportation fear induced by the roll-out of Secure Communities (SC), a far-reaching immigration enforcement program, affected the demand for safety net programs in the United States. We estimate the spillover effect of SC on the take-up of federal means-tested programs by Hispanic citizens, who are not themselves eligible for removal. We find significant declines in SNAP and SSI enrollment, particularly among mixed-citizenship status households. The response is muted for Hispanic households residing in sanctuary cities. Our results are most consistent with network effects that perpetuate fear rather than lack of benefit information, measurement error, or stigma.

\author{
Marcella Alsan \\ Stanford Medical School \\ Center for Health Policy/PCOR \\ 117 Encina Commons, Room 218 \\ Stanford, CA 94304 \\ and NBER \\ malsan@stanford.edu \\ Crystal Yang \\ Harvard Law School \\ Griswold 301 \\ Cambridge, MA 02138 \\ and NBER \\ cyang@law.harvard.edu
}

An online appendix is available at http://www.nber.org/data-appendix/w24731 


\section{Introduction}

Active enrollment in safety net programs in the United States is far from complete despite mounting evidence of high returns to health and human capital (Ashenfelter 1983, Currie 2006) 1] This incomplete take-up varies across racial and ethnic groups. In general, Hispanic citizens have lower participation than African-Americans and non-Hispanic whites across a range of public welfare programs (Morin, Taylor, and Patten 2012) $\left.\right|^{2}$ Moreover, the gap between take-up by eligible Hispanics versus other groups has widened in recent years. For example, between 2005 and 2013, the share of Hispanics taking up the Supplemental Nutrition Assistance Program (SNAP) decreased by 12.6 percentage points relative to other groups despite increasing food insecurity for Hispanic households (Nord, Andrews, and Carlson 2006; Coleman-Jensen, Gregory, and Singh 2014), and the share of Hispanics taking up Supplemental Security Income (SSI) fell by 14.8 percentage points relative to non-Hispanics ${ }^{3}$

Many scholars have studied the factors that influence program participation, including transaction costs, information, and stigma (e.g. Aizer 2007; Besley and Coate 1992), in addition to behavioral biases such as inattention and time-inconsistency (Bhargava and Manoli 2015; Madrian and Shea 2001; Karlan et al. 2016). Widening the lens beyond individual psychology and constraints, studies also suggest that social networks influence the take-up of programs in the United States. For example, Bertrand, Luttmer, and Mullainathan (2000) focus attention on the role such networks can play in reducing participation costs, potentially via improved information and destigmatization. Dahl, Kostøl, and Mogstad (2014) demonstrate that receipt of welfare programs in one generation increases receipt in the next, and Borjas and Hilton (1996) find that prior ethnicspecific program participation predicts take-up by future waves of immigrants, evidence consistent with the intergenerational transmission of ethnic capital (Borjas 1992). For U.S.-based Hispanic communities, however, social networks may not only facilitate but also deter program participation via the spread of fear.

In this paper, we explore whether deportation fear explains some of the puzzle of incomplete take-up, specifically for Hispanic Americans. Recent survey evidence suggests that deportation fear is widespread. In a 2017 survey of residents in Los Angeles County, 37 percent reported being concerned that they, a friend, or a family member could be deported. Among those who endorsed such a concern, 80 percent said that they, a friend, or family member would be at greater risk of being deported by enrolling in a government health, education, or housing program 4 Pedraza

\footnotetext{
${ }^{1}$ For evidence on the health and human capital returns, see Almond et al. (2011); Hoynes, Schanzenbach, and Almond (2016); Bronchetti, Christensen, and Hoynes (2018); Almada and Tchernis (2018); East (2018); Aizer et al. (2016); Goodman-Bacon (2018b).

${ }^{2}$ According to Morin et al. (2012), across the six best-known federal entitlement programs, 64 percent of blacks reported taking up any of these programs compared to 56 percent of whites and 50 percent of Hispanics. Blacks are also more likely than whites or Hispanics to have received three or more benefits (27 percent for blacks vs. 14 percent for whites and 11 percent for Hispanics).

${ }^{3}$ Authors' own calculations from the American Community Survey. In addition, among households participating in SNAP, the Hispanic share fell from 13.3 percent in 2006 to 11.8 percent in 2016 (Wolkwitz 2007; Lauffer 2017).

${ }^{4}$ Data from 2017 UCLA Luskin Los Angeles Quality of Life Index Survey. Specifically, the survey asks the following two questions: (1) "Switching gears a bit, are you worried that you, a friend of yours or a member of your
} 
and Osorio (2017) show that simply priming Latino respondents on immigration during surveys led respondents to reduce their stated willingness to engage in public services. These findings echo other qualitative evidence suggesting Hispanic citizens, themselves immune to deportation, nevertheless fear that enrollment may reveal personal information on non-citizens in their networks to immigration authorities. As reported in PBS News Hour, "You don't want to be the family member that because you signed up for coverage you're getting your grandmother, your uncle or your parent deported.' ${ }^{5}$ Yet causal evidence on whether federal enforcement targeting non-citizens spills over to influence the safety net participation of citizens not at personal risk of deportation remains thin.

To make progress on this question, we study the introduction of a far-reaching immigration enforcement program known as Secure Communities (SC). SC is a federal program administered by the U.S. Immigration and Customs Enforcement Agency (ICE) from 2008 to 2014, and re-activated in 2017. The program empowers ICE to check the immigration status of anyone arrested by local law enforcement agencies through fingerprint analysis and substantially increases the likelihood that a non-citizen immigrant will be deported conditional on being arrested. From its activation to its discontinuance in 2014, SC has led to over 43 million fingerprint submissions, 2.2 million fingerprint matches, and over 380,000 individuals forcibly removed from the interior. Removals under the Obama administration's implementation of SC comprised twenty percent of the approximately two million total removals during the time period, the highest number in recent U.S. history 6

As we are focused on the spillover effects of immigration enforcement on Hispanic citizens, we distinguish between direct and indirect treatment effects, with a focus on the latter. In the potential outcomes framework, the direct treatment effect is the difference in potential outcomes for treatment and control groups among individuals who are eligible for treatment (Rubin 1974). Treatment in our context is defined as immigration enforcement under SC and those eligible for deportation are non-citizen immigrants. 7 Direct treatment effects stem mainly from principal-agent problems, whereby non-citizen parents forgo signing up their citizen children for benefits out of fear of revealing themselves. Estimating direct effects has been the subject of several studies in public health (Vargas and Pirog 2016; Hacker et al. 2011; Vargas and Ybarra 2017) as well as important work in economics by Watson (2014) and Amuedo-Dorantes, Arenas-Arroyo, and Sevilla (2018).

In sharp contrast, indirect treatment effects stem from externalities, whereby citizen decisionmakers forgo private benefits out of concern for their non-citizen contacts. In our context, indirect treatment effects measure the difference in potential outcomes for treatment and control groups among individuals who are not eligible for deportation (i.e. authorized U.S. citizens), who may nevertheless be fearful of revealing non-citizen family members, such as spouses or parents, or other

family will be deported from the United States because of their immigration status?" and (2) "Are you worried that you, a friend of yours or a member of your family will be at a greater risk of being deported by enrolling in a government health care, education or housing program?"

${ }^{5}$ See https://www.pbs.org/newshour/health/hispanic-americans-still-arent-signing-obamacare

${ }^{6}$ See 2016 Yearbook of Immigration Statistics at https://www.dhs.gov/immigration-statistics/yearbook/2016/ table39

'By federal law, any non-citizen can be deported, including unauthorized individuals and green card holders. 
members of the community. A simple extension to Moffitt's canonical model of welfare participation (1983), contained in the Online Appendix, nests both the direct and indirect treatment effects and formalizes the mathematical distinction between the two of them.

To estimate spillover effects, we use detailed micro-data on the universe of over two million detainers ("immigration holds") issued under SC between 2008 and 2013. These data contain information on the county of issue, crime severity, and country of origin of each arrested individual. We combine these data with information on the take-up of the Supplemental Nutrition Assistance Program (SNAP), otherwise known as food stamps, and take-up of Supplemental Security Income (SSI). Information on take-up comes from public-use data from the American Community Survey (ACS) and restricted-use data from the Panel Study of Income Dynamics (PSID). We focus on these federal programs as they have fairly uniform eligibility requirements across locations that exclude unauthorized individuals, allowing us to estimate indirect treatment effects. SNAP and SSI also represent two of the largest means-tested programs in the United States and thus are of special interest to economists and policymakers alike. For both safety net outcomes, we examine behavioral responses among a sample of economically fragile households that are connected with non-citizens, defined as those in which the head of household earned less than a high school degree 8

We estimate the impact of SC on program take-up by leveraging the staggered roll-out of SC across counties together with the fact that Hispanic households were differentially affected. This latter variation is appropriate since well over 90 percent of detainers issued under the SC program were for Hispanics. We use a triple-differences framework, interacting race and ethnicity indicators with timing of SC activation. In doing so, we compare program take-up for Hispanic households within a given location to take-up for non-Hispanic whites and blacks, net of counties that had not yet activated, before versus after SC activation. The triple-differences identification assumption is plausible, requiring that there be no location-specific shocks timed with the staggered SC roll-out and influencing the dynamic path of safety net outcomes exclusively for Hispanics while sparing other minority groups.

$\mathrm{SC}$ activation is associated with substantial declines in safety net participation among Hispanic citizen households. In the ACS, Hispanic-headed families are 2.1 percentage points less likely to take up food stamps after activation of SC. The take-up rate of food stamps among Hispanic-headed households in the ACS before activation was 21 percentage points, implying a ten percent decline in take-up due to SC activation. Hispanic households are also 1.6 percentage points less likely to take up SSI after SC activation, a 30 percent decline relative to the pre-SC Hispanic mean. We obtain qualitatively similar results when using the PSID, finding a decline in both Hispanic food stamp and SSI take-up.

A number of findings suggest these results are indeed causal. First, consistent with the parallel trends assumption under our triple-differences approach, we find no sharp changes in the evolution of our outcome variables prior to SC activation. Second, our preferred specification includes a full set of race-by-state fixed effects to address the potential concern that states may vary in policies

\footnotetext{
${ }^{8}$ We find similar though smaller effects for households with a high school degree and those with some college.
} 
towards minority groups, state-by-year fixed effects to account for changes in state-level immigration enforcement such as the enactment of omnibus enforcement bills (Amuedo-Dorantes and ArenasArroyo 2017), and race-by-year fixed effects, county-by-time fixed effects, along with state- and group-specific employment changes during the Great Recession to allow for flexible impacts of the Great Recession across demographic groups (Kochhar, Fry, and Taylor 2011; McKernan et al. 2014). Third, we show SC only affected Hispanic Americans - results on program take-up for non-Hispanic blacks or whites are often oppositely-signed and not statistically significant, consistent with the notion that the SC program should not affect the behavior of those less likely to be affected by enhanced immigration enforcement.

Because our focus is on indirect effects, we examine program participation among heads of households that are citizens. A ubiquitous challenge for enforcement-related research is that enforcement itself could alter the veracity and completeness of survey responses. Indeed, Census researchers with privileged access to Social Security files linked to the ACS find that individuals classified as noncitizens in administrative records (AR) are less likely to respond to the citizenship question (Brown et al. 2018). These researchers also document that citizenship misrepresentation is concentrated among recently arrived foreign-born individuals 9

To address these measurement concerns, we do not rely exclusively on responses to the ACS citizenship question to ascribe status. Informed by the Brown et al. (2018) report, we define citizens as those born in the U.S. or those who have resided in the U.S. for over a decade and are naturalized 10 We then gauge the accuracy of this citizenship measure by comparing our survey-derived naturalization counts to administrative counts published by the Office of Immigration Statistics, finding that the correlation between the two is 0.94. Furthermore, neither the fraction of Hispanic citizens in the ACS nor the relevant sample weight responds to the introduction of SC. Inaccurate reporting of in-kind transfers on surveys, as uncovered by Meyer, Mittag, and Goerge (2018), could pose additional analytical challenges. Although there exists a sizable difference between state-level administrative records and ACS-reported SNAP enrollment, we find that immigration enforcement does not alter the evolution of this gap.

In the penultimate section of the paper, we explore potential explanations for why Hispanic citizens would reduce their take-up of safety net programs relative to other citizen groups in the face of immigration enforcement. We report six findings that, taken together, are difficult to reconcile without invoking fear as the dominant explanatory mechanism. Fear is the subjective likelihood of an event that brings disutility (Becker and Rubinstein 2011). Whether detention or deportation of a non-citizen elicits such a response depends on whether the citizen decision-maker is connected to someone who is deportable. We therefore assess changes in program participation among communities with a higher share of non-citizens or mixed-status Hispanic-headed households 11 We find

\footnotetext{
${ }^{9}$ Note that our proposal to access restricted versions of data in the Federal Research Data Center (FRDC) was denied by Census due to subject matter.

${ }^{10}$ Specifically, we define citizenship using the following questions in the ACS: (1) Where was this person born?; (2) When did this person come to live in the United States?; and (3) Is this person a citizen of the United States?

${ }^{11}$ Mixed-status households include members that have different citizenship or immigration statuses.
} 
that reductions in safety net take-up are largest among said locations. Second, we find that places where detainers are more commonly issued against Hispanics for non-violent (e.g. misdemeanors) than violent crimes exhibit a larger response to SC, suggesting that the failure to target serious non-citizen offenders generates a stronger behavioral response. Third, locations where deportation fear rises over the activation period, as measured in Pew survey data, exhibit a heightened response to the program's introduction. Fourth, in locations where federal detainers are not uniformly enforced (i.e. "sanctuary cities"), SC activation has almost no detectable effect. Fifth, locations with a higher share of Puerto Ricans and Cubans, groups that face zero to minimal risk of deportation relative to Hispanics from other countries of origin, have muted responses to SC. Finally, we show that, following SC activation, Google searches for deportation-related terms across media markets increased sharply, consistent with at least an awareness of the program if not fear of its potential consequences.

One competing explanation for our results is information. Since social networks transmit not only fear but also detailed programmatic knowledge, reducing the number of co-ethnics who sign up for a program could leave affected groups poorly informed about benefits. We explore this possibility following Aizer and Currie (2004) by estimating effects on households that previously took up food stamps or SSI prior to SC activation. Such households arguably already know how to sign up for the benefit. Similar to Aizer and Currie (2004), we find that information spillovers are not an important part of the explanation: Hispanic individuals in households who previously used food stamps or SSI also substantially reduced their use following SC activation. We also explore but reject the possibility that compositional changes in the types of Hispanic individuals responding to survey questions in a given locale due, for example, to migration, are driving the results. In addition, we fail to find significant effects of SC on employment, suggesting that our findings are unlikely driven by changes in labor force attachment among Hispanics.

In sum, our findings suggest that Hispanic citizens respond to recent immigration enforcement by reducing their safety net participation, likely due to fear of revealing non-citizens in their networks. Our results imply that deportation fear plays an important role in explaining some of the uptake gap for Hispanic Americans, with potentially adverse long-term consequences for the health and well-being of Hispanic families.

Our paper contributes to research in the fields of economics, law, political science, and public health. Prior research examining the effects of immigration enforcement focuses on non-citizens - in particular, the reluctance of unauthorized parents to sign up their citizen children for government programs. For instance, Watson (2014) and Pedraza and Zhu (2014) find that immigration enforcement suppresses children's Medicaid enrollment by their non-citizen parents. Similarly, Vargas and Pirog (2016) find declines in Women, Infants, and Children (WIC) participation, a program legally available to unauthorized immigrants, among non-citizen mothers. On the other hand, amnesty to undocumented individuals increases their tax filing and take-up of the Earned Income Tax Credit (Cascio and Lewis 2019) ${ }^{12}$ We extend the above literature by providing the first causal estimates

\footnotetext{
${ }^{12}$ These empirical studies are complemented by qualitative work regarding fears about the personal risk of detention
} 
of the indirect effect of immigration enforcement on the choice behavior of Hispanic citizens.

Second, we add to the literature seeking to understand why families sometimes forgo participation in safety net programs despite high returns (see review by Currie 2006), highlighting that kinship networks can yield not only benefits, but also impose costs (see review by Cox and Fafchamps 2008; di Falco and Bulte 2011). Third, by providing novel metrics of deportation fear, we contribute to scholarship that aims to quantify the effect of fear on consumer behavior (Slemrod 1990; Becker and Rubinstein 2011).

Our paper proceeds as follows. The next section describes the SC program in detail. Section III discusses eligibility rules for public programs in the study. Section IV describes our conceptual framework and Section V outlines our data and identification strategy. Section VI reports the results, Section VII discusses potential mechanisms, and Section VIII concludes.

\section{Background on Secure Communities}

Secure Communities was an immigration enforcement program administered by ICE from 2008 to 2014 and reactivated in $2 0 1 7 \longdiv { 1 3 }$ The program was aimed at helping ICE arrest and remove individuals who were in violation of federal immigration laws, including those who failed to comply with a final order of removal, or those who had engaged in fraud/willful misrepresentation in connection with government matters. SC had three main objectives: (1) to identify non-citizens at large and in federal, state, and local custody charged with or convicted of serious criminal offenses who were subject to removal; (2) to prioritize enforcement actions to ensure apprehension and removal of non-citizens convicted of serious criminal offenses; and (3) to transform enforcement processes and systems to achieve lasting results. SC accomplished these goals through an extensive collaboration between state and local law enforcement agencies, the Federal Bureau of Investigation (FBI), and the Department of Homeland Security (DHS).

Typically, when a person is arrested and booked by a state or local law enforcement agency, his or her fingerprints are taken and submitted to the FBI. The FBI runs these fingerprints in order to conduct a criminal background check, which is forwarded to the state or local authorities. Prior to the implementation of SC, non-citizens in violation of immigration laws were identified by inmate interviews in local jails or prisons, performed by either federal officers under a policy known as the Criminal Alien Program (CAP) or local officers under formal written agreements with DHS, known as $287(\mathrm{~g})$ agreements. These interviews were labor-intensive, such that federal and local officials authorized to conduct these interviews screened less than 15 percent of local jails and prisons, and in only about two percent of all U.S. counties (Cox and Miles 2013).

$\mathrm{SC}$ improved upon the standard fingerprinting procedure. Under SC, fingerprints received by the FBI were automatically and electronically sent to DHS. Legally, this information exchange fulfills

or deportation leading undocumented immigrants and their U.S. citizen children to avoid health programs (Yoshikawa 2011; Bean, Brown, and Bachmeier 2015), with the consequence of expanding ethnic and racial health disparities (Asad and Clair 2018). See also Cruz Nichols, LeBrón, and Pedraza (2018).

${ }^{13}$ Additional institutional details on the program and its implementation can be found in the Online Appendix. 
a 2002 Congressional mandate for federal law enforcement agencies to share information that is relevant to determine the admissibility or deportability of an individual (8 U.S.C. $\$ 1722(\mathrm{a})(2)$ ). The fingerprints received by DHS were then compared against its Automated Biometric Identification System (IDENT), a database that stores biometric and biographical information on foreign-born persons in three primary categories: (1) non-citizens in the U.S. who have violated immigration law, such as persons who were previously deported and/or overstayed their visas; (2) non-citizens lawfully in the U.S. but who may be deportable if they are convicted of the crime for which they have been arrested; and (3) citizens who naturalized after their fingerprints were included in the database (see Cox and Miles 2014). IDENT contains the fingerprints of suspected terrorists, criminals, immigration violators, in addition to all travelers when they enter and leave through U.S. airports, seaports, and land border ports of entry; and when they apply for visas at U.S. consulates. The IDENT system was created in 1994 to help U.S. border and immigration officials keep criminals and terrorists from crossing U.S. borders.

If there was a fingerprint match, ICE relied on both biometric confirmation of the individual's identity in addition to other reliable evidence that the individual either lacks immigration status or is removable under immigration law. If ICE had probable cause for removability, they then issued what is called a "detainer" (sometimes called an "immigration hold") on the person. This detainer requested that the state or local law enforcement agency hold the individual for up to 48 hours to allow ICE to assume custody for the initiation of removal proceedings. As a result of this detainer protocol, individuals who may otherwise be released through the local legal system (such as those whose cases were dismissed or those who were released pre-trial pending criminal proceedings) were detained via SC. As Cox and Miles (2014) describe, SC substantially increased the likelihood that a non-citizen would be apprehended by ICE and deported from the country, conditional on being arrested. According to an official review of SC in 2011, in most cases, people detained by ICE were subject to immigration enforcement action for reasons independent of the triggering arrest or conviction, i.e., a fingerprint match may indicate that the person was removable because he or she entered the country without inspection or overstayed a visa.

Notably, state and local jurisdictions could not easily opt out of SC. All fingerprints submitted to the FBI were automatically sent to DHS as a result of the information-sharing partnership, such that a local jurisdiction could not choose to only submit its fingerprints to the FBI 14 When SC was first activated, Secretary of Homeland Security Janet Napolitano described the program as follows: "Secure Communities gives ICE the ability to work with our state and local law enforcement partners to identify criminal aliens who are already in their custody, expediting their removal and keeping our communities safer.'15 SC was also described as a partnership between ICE and each state's State Identification Bureau, requiring a memorandum of agreement (MOA) between the ICE acting director and State Identification Bureau officials 16 However, in the spring of 2011,

\footnotetext{
${ }^{14}$ See http://www.washingtonpost.com/wp-dyn/content/article/2010/09/30/AR2010093007268.html

15 https://www.dhs.gov/news/2010/08/10/secretary-napolitano-announces-secure-communities-deployment-allsouthwest-border.

${ }^{10}$ See MOA at https://www.ice.gov/doclib/foia/secure_communities/securecommunitiesmoatemplate.pdf
} 
governors in Massachusetts, New York, and Illinois ended their respective MOAs with DHS. The three states alleged that the program was not exclusively targeting the most violent offenders and was hindering community policing. ICE subsequently determined and clarified that the MOAs were "not required to activate or operate Secure Communities in any jurisdiction." [17 Shortly thereafter, John Morton, former Director of ICE, terminated all MOAs in August 2011 in the "Morton Memo," stating they had led to "substantial confusion" and that "ICE has determined that an MOA is not required to activate or operate $\mathrm{SC}$ for any jurisdiction ... Once a state or local law enforcement agency voluntarily submits fingerprint data to the federal government, no agreement with the state is legally necessary for one part of the federal government to share it with another part.'18

Due to various technological constraints, SC was not implemented at once across the entire country. As noted by Cox and Miles (2013), one of the main technological hurdles was that many jurisdictions did not have live scan fingerprint devices. We discuss the roll-out of SC and the nontechnological factors that influenced it further below. The program began on October 27, 2008, and was activated on a county-by-county basis. SC was adopted in most counties by mid-2012 and fully activated across the entire country on January 22, 2013. Cox and Miles (2013) show that the timing of activation across counties is most strongly correlated with the Hispanic population, distance from the Mexican border, and whether a county had a 287(g) agreement with ICE, findings we return to when discussing our identification strategy below.

In response to SC, some jurisdictions began to disobey detainer requests from ICE, arguing such detentions were unconstitutional under the Fourth Amendment, as well as noting concerns that such practices would discourage immigrant cooperation with local law enforcement. These jurisdictions became known as "sanctuary cities.'19

On November 20, 2014, SC was temporarily suspended across the entire country by DHS policy, in part due to the resistance from sanctuary cities. After SC was suspended, DHS implemented a new program called the "Priority Enforcement Program" (PEP). Under PEP, ICE continued to rely on fingerprint-based biometric data submitted during bookings by state and local law enforcement agencies. However, ICE was instructed to only transfer individuals who were convicted of specifically enumerated high priority offenses, individuals who intentionally participated in an organized criminal gang to further the illegal activity of the gang, or individuals deemed to pose a danger to national security. In addition, ICE was instructed to only request a detainer if the person in custody was subject to a final order of removal or if there was other sufficient probable cause to find that the person was removable. On January 25, 2017, SC was reactivated under Executive Order No.

\footnotetext{
${ }^{17}$ http://www.ncsl.org/research/immigration/secure-communities.aspx.

${ }^{18}$ See pg. 7 of Task Force on Secure Communities: Findings and Recommendations, https://www.dhs.gov/ xlibrary/assets/hsac-task-force-on-secure-communities-findings-and-recommendations-report.pdf.

${ }^{19}$ The specific policies can vary widely, from prohibiting police officers inquiring about a person's immigration status, to not honoring administrative detainers issued by ICE, to restricting information sharing with federal immigration agents. For an up-to-date map of sanctuary cities and counties across the United States, see http://cis.org/Sanctuary-Cities-Map and https://www.ilrc.org/local-enforcement-map Importantly, the number of detainers could not be meaningfully influenced by sanctuary cities unless they chose to not arrest Hispanic individuals. There is no evidence this was a strategy pursued by these jurisdictions. Rather they ignored detainer requests. See https://www.dhs.gov/sites/default/files/publications/14_1120_memo_secure_communities.pdf
} 
13768, entitled Enhancing Public Safety in the Interior of the United States. From its inception in 2008 through 2014 and since its reactivation in 2017, SC has led to the deportation of over 400,000 immigrants and continues to increase.

\section{Safety Net Programs}

In this study, we focus on participation in SNAP and SSI, two of the largest means-tested programs in the United States. SNAP participation increased from 20 million to 40 million participants between 1990 and 2010 and reached record levels of spending - \$78 billion - in 2011 (CBO 2012). SSI participation has also grown substantially over time, rising from 4.6 million beneficiaries in 1989 to 8.4 million in 2013, with the federal government paying $\$ 54$ billion in SSI cash benefits in 2013 (Daly and Burkhauser 2003; Duggan, Kearney, and Rennane 2016). Moreover, both have fairly uniform eligibility requirements that exclude unauthorized individuals, thus enabling us to measure indirect treatment effects. We summarize the eligibility requirements below.

SNAP/Food Stamps: The Supplemental Nutrition Assistance Program (SNAP), previously known as the Food Stamp Program, is the largest near cash means-tested transfer program in the U.S. In 2012, SNAP spending reached $\$ 74$ billion, exceeding spending on both the Earned Income Tax Credit (\$64 billion) and Temporary Assistance for Needy Families (\$29 billion) (Hoynes et al. 2016). SNAP is also the only U.S. public safety net program that is universally available to low-income people without many other restrictions such as being disabled, elderly, or having children. The program has been credited with helping lift families out of poverty every year and for acting as a stabilizer during the Great Recession (Tiehen et al. 2012; Ganong and Liebman 2018; Short 2014; Bitler and Hoynes 2015).

In order to receive benefits under SNAP, individuals need to meet various federal guidelines ${ }^{20}$ In general, households must have an annual income below 130 percent of the federal poverty line. Further, applicant households must have less than $\$ 2,250$ in countable resources $(\$ 3,500$ if someone is older than 60 or disabled) ${ }^{21}$

Immigrants residing in the country without authorization are ineligible to receive benefits. In contrast, qualified legal immigrants (i.e. green card holders and other qualified aliens such as parolees and refugees) are eligible for SNAP if they have lived in the U.S. for five years, if they currently receive disability-related assistance, or if they are children under 18 , in addition to the income and resource limits. To apply for benefits, individuals complete an application in-person or online, followed by an interview with a SNAP representative. In our context, immigration enforcement may affect take-up because SNAP applications routinely ask for the names, citizenship status, and Social Security numbers of all persons in the household, regardless of whether they are applying for

\footnotetext{
${ }^{20}$ See https://www.fns.usda.gov/snap/eligibility\#Resources

${ }^{21}$ The household can forego the SNAP income test, however, if all members of the household are receiving TANF, SSI, or some other state general assistance programs. There is no requirement of employment in most cases, but applicants have to meet certain work conditions, including registering for work and not voluntarily reducing work hours. See detailed reviews on safety net requirements for further information. See https://www.fns.usda.gov/snap/ eligibility
} 
benefits. Some states also ask for country of origin, date of entry, and alien registration number for each person in the household. Using this information, states verify the immigration status of each household member through DHS via the Systematic Alien Verification for Entitlements (SAVE) program, designed to reduce benefit fraud. An example of a state SNAP form is provided in Appendix Figure A1.

Almost all states assure applicants that their information will only be used to determine eligibility and will not be shared with ICE. For example, the California Department of Social Services states that immigration status "can only be used to determine...eligibility, and cannot be used for immigration enforcement.22 Nevertheless, advocacy groups claim that SNAP applications have declined recently and that this decline has coincided with increased anti-immigration rhetoric. As a SNAP outreach coordinator for the Latino community noted to the Washington Post, "They're staying away from me...I say hi to them, and they avoid me completely. I don't know what they've been saying amongst themselves. But no one is signing up anymore, and the people who need to renew are not renewing. 23

SSI: Supplemental Security Income (SSI), administered by the Social Security Administration (SSA), is the largest cash welfare program in the United States (Daly and Burkhauser 2003, Deshpande 2016). In addition to federal assistance, which provided a maximum for an individual of $\$ 733$ per month in 2016, almost one-third of states supplement the federal benefit with state SSI benefits (Duggan et al. 2016). SSI provides benefits to blind or disabled children, blind or disabled workingage adults, and individuals 65 or older with no requirement of disability, although its caseload is increasingly dominated by disabled children and non-elderly adults. Between 1988 and 2013, total federal benefits paid for SSI disabled children and non-elderly adults nearly tripled, increasing from $\$ 14.6$ billion to $\$ 44.4$ billion dollars in 2013 (Duggan et al. 2016). This program is aimed at providing an income floor to individuals who are ineligible for Social Security or whose benefits could not provide a basic living. In fact, for nearly three-fifths of recipients, SSI represents their only source of income (US SSA 2013). Child participation in SSI has been linked with significant and persistent reductions in child poverty rates (Duggan and Kearney 2007).

To be eligible for SSI, individuals must be aged or disabled and meet federally mandated income and asset limits. In general, individuals with "countable income" over the federal benefit rate are not eligible for SSI. Individuals must also meet asset limits and have no more than $\$ 2,000$ in assets or $\$ 3,000$ for a couple. Like SNAP, only U.S. citizens, U.S. nationals, or "qualified aliens" are eligible for SSI. Unauthorized individuals are not eligible for SSI.

Upon meeting the above requirements, individuals must also meet one of three categorical criteria: age, disability or blindness. Elderly individuals are automatically eligible for SSI based on age if they are age sixty-five or older. Individuals may receive SSI benefits for blindness if they have

\footnotetext{
${ }^{22}$ See http://www.cdss.ca.gov/cdssweb/entres/forms/English/SAWS2ASAR.pdf and http://www1.nyc.gov/ assets/hra/ACCESSNYC/pdf/SNAPKit/english/LDSS 4826A.pdf.

${ }^{25}$ See https://www.washingtonpost.com/news/wonk/wp/2017/03/16/immigrants-are-now-canceling-their-foodstamps-for-fear-that-trump-will-deport-them/?utm_term=.be2800772b3a
} 
$20 / 200$ vision or worse with the use of a correcting lens in their better eye, or if they have tunnel vision of 20 degrees or less.

Non-elderly adults with a disability typically apply for SSI through an SSA field office, where SSA employees determine both income/asset eligibility and disability. State disability examiners, working with vocational and medical consultants, conduct medical determinations. To meet the disability determination, a non-elderly adult must demonstrate an inability to engage in substantial gainful activity by reason of a medically determinable physical or mental impairment that is expected to result in death or last at least twelve months. The process for disability determination for children similarly requires that a child has a disability lasting at least twelve months or expected to result in death. Applicants who are initially rejected may appeal the decision.

Like with SNAP, immigration enforcement may affect take-up because the SSI application asks for the names, birthdates, and Social Security numbers of all persons living with the applicant. This portion of the SSI application is provided in Appendix Figure A2. Questions about household composition are taken into account to determine the contribution of the applicant to household expenses such as rent and utilities and can affect the amount of the SSI federal benefit ${ }^{24}$ Anecdotally, being asked to provide this type of information has invoked fear among certain communities given that federal benefits-granting agencies, in particular SSA for the administration of SSI, are required to report to DHS individuals who have undergone a formal determination on a claim who the agencies know are not lawfully present in the United States ${ }^{25}$ However, according to the National Immigration Law Center, these agencies have clarified that this reporting requirement is only triggered for individuals seeking benefits and not relatives or household members. ${ }^{26}$

\section{Conceptual Framework}

In the Online Appendix, we adapt Moffitt's (1983) seminal model of non-participation in social programs and formalize how immigration enforcement can lead to spillover effects on Hispanic citizens. Agents maximize expected household utility placing weights on each set of family members - citizens and non-citizens. Instead of a stigma cost associated with participation, however, we include a deportation cost that is increasing in safety net participation and immigration enforcement. Under this model, the household decision-maker sets the marginal benefit of participation in federal programs, weighted by the welfare importance of citizen household members, equal to the marginal deportation cost induced by participation, weighted by the welfare importance of noncitizen members. Participation thus increases in the size of the program benefit and the weight given to eligible citizens in the household, but declines with immigration enforcement and the weight given to non-citizen household members.

\footnotetext{
${ }^{24}$ See https://www.ssa.gov/ssi/spotlights/spot-living-arrangements.htm

${ }^{25}$ See Personal Responsibility and Work Opportunity Reconciliation Act of 1996, Public Law 104-193, §404. SSA also routinely honors requests to share social security number information with DHS and ICE under an information sharing requirement in the Immigration and Nationality Act (8 U.S.C. $§ 1360(b))$. See https://secure.ssa.gov/poms. nsf/lnx/0203313095.

${ }^{20} \mathrm{See}$ https://www.nilc.org/issues/economic-support/overview-immeligfedprograms/
} 
When the household decision-maker is a U.S. citizen, the decision-maker forgoes a personal entitlement benefit to avoid the deportation cost incurred by close non-citizen contacts - this is precisely the indirect spillover effect we aim to identify in this paper. By contrast, when the household decision-maker is an ineligible non-citizen, the decision-maker does not forgo any benefits for himself. Rather, participation decisions are made on behalf of other household members, such as enrollment in Medicaid or subsidized school lunches for citizen children. In this scenario, a noncitizen decision-maker's decision to enroll others directly increases the decision-maker's own risk of deportation 27

\section{Data and Empirical Framework}

Our goal is to estimate the causal effect of immigration enforcement on take-up of various public services by citizen Hispanic Americans. In this section, we provide an overview of the data sources, describe our identification strategy to draw causal inference, and address measurement concerns.

\section{A. Data}

$S C$ Data on Detainers and Removals: Through records available to the public, FOIA requests to ICE, and restricted-use data agreements, we have obtained data on the roll-out of SC as well as micro-level data on the universe of detainers issued by ICE from 2002 to 2015 in the United States (US ICE 2015, TRACFED 2016). The detailed information includes the reason for the arrest as well as the crime level/severity, the date the detainer was issued, the county the detainer was issued in, the individual's country of origin, and other individual-level demographics (age and sex). We also have the universe of individuals who were removed (actually deported) from the country due to a fingerprint match under SC from 2008 to 2015, in addition to county-level yearly data on the number of fingerprint submissions and matches under SC from 2008 to 2015.

Panel A of Figure 1 presents the total number of detainers issued per year and Panel B presents the cumulative number of detainers issued over the time period. The rapid ramp up in SC is evident in the time immediately following SC's launch in 2008. These figures also demonstrate that the overwhelming majority (93 percent) of detainers are issued against Hispanic individuals. Panel $\mathrm{C}$ presents the ratio of detainers for low-level offenses (e.g. misdemeanor offenses) versus serious, violent offenses and shows that, over time, SC issued a growing share of detainers for low-level arrests. While not all detainers are honored by local law enforcement agencies or lead to removal from the country, there is a strong positive correlation between detainers and removals under SC. See Appendix Figure A3.

$\mathrm{SC}$ represented a massive increase in immigration enforcement. Appendix Table A1 presents difference-in-differences estimates of the impact of SC activation in a county on enforcement. Consistent with Cox and Miles (2014), we find that SC activation had no significant effect on offenses

\footnotetext{
${ }^{27}$ See Online Appendix D for more detail and the distinction between indirect and direct treatment effects depending on the citizenship status of the household decision-maker. Specifically, compare the participation threshold in the indirect case: $\frac{\left(\lambda_{i}+\lambda_{c}\right) \cdot\left(B_{j}\right)}{\lambda_{n}}=\gamma_{j}$, to the direct case: $\frac{\lambda_{c} \cdot\left(B_{j}\right)}{\lambda_{i}+\lambda_{n}}=\kappa_{j}$.
} 
known to law enforcement. In contrast, we find significant increases in the number of fingerprint submissions received by ICE, fingerprint matches, and detainers issued post-SC activation. Event study estimates of the impact of SC on detainers issued are presented in Appendix Figure A4, which shows a sharp 15 percent increase in the number of detainers issued in the several months post-SC activation with no discernible trend pre-SC activation.

American Community Survey: We use publicly available ACS data downloaded from IPUMSUSA at the University of Minnesota (Ruggles et al. 2019). We focus on the one percent ACS samples of the U.S. population over the years 2006-2016 for food stamp and SSI take-up. The data include household characteristics such as food stamp and SSI receipt in the last year and also individual characteristics like education, natality, and citizenship status. The most detailed level of geography in the publicly available ACS is the Census-defined Public Use Microdata Areas (PUMA). PUMAs contain at least 100,000 people and can cross county but not state lines. Because our activation dates and detainers data are at the county level, we distribute the ACS means at the PUMA level to counties based off the PUMA population in each county 28

Panel Study of Income Dynamics: We use data from the restricted-access Panel Study of Income Dynamics (PSID) from 2005-2015 (PSID 2017). The PSID data are biennial, following heads of household in every survey round. The data contain detailed information on food stamp and SSI take-up within the past 12 months and ethnicity by households at the county level. While the PSID does not ask about citizenship status, we proxy for citizenship status using whether a household head grew up in the United States versus a foreign country or whether the household head's mother and father were both born in the United States. The PSID added immigrants and their adult children in the 1997 wave and dropped some core families to better reflect the changing demographics of the United States (PSID 2000). PSID household characteristics include family size, number of children, household poverty, and head characteristics include employment status and disability.

Google Trends Data: To measure awareness and perhaps deportation fear in response to SC, we use data from internet search patterns provided by Google Trends. Google Trends is a publicly available database that provides information on the relative popularity of search terms for 250 metropolitan areas across the United States at the Nielsen DMA media markets level. As discussed in Burchardi, Chaney, and Hassan (2018), for each search term $i$ in media market $d$, the Google Trends tool provides the normalized share of searches (out of 100) that contain the search term:

$$
G(i, d)=\left[100 \cdot \frac{\operatorname{share}(i, d)}{\max _{\delta}\{\operatorname{share}(i, \delta)\}} \mathbb{1}[\#(i, d)>T]\right]
$$

where $\operatorname{share}(i, d)$ is the share of searches in $d$ that contains $i, T$ is a threshold value of searches that must be exceeded for Google to permit access to the data, and $\max _{\delta}\{\operatorname{share}(i, \delta)\}$ represents the

\footnotetext{
${ }^{28}$ We use crosswalks provided by the University of Michigan Institute for Social Research and the Missouri Census Data Center. See http://www.psc.isr.umich.edu/dis/census/Features/puma2cnty/ and http://mcdc.missouri.edu/ websas/geocorr14.html. Appendix Table A3 column 6 repeats the analysis at the PUMA-level.
} 
maximum share of searches that contain $i$ across all media markets $\delta$. Thus, under this expression, $G(i, d)$ is equal to 100 in the metro area with the largest share of searches containing $i$ and equal to a positive number smaller than 100 in all other metro areas that have a sufficient number of searches containing $i$.

We use the following commonly searched terms related to the Deportation topic on Google Trends: deportation, deportacion, immigration, inmigracion, immigration lawyer, abogados de inmigracion, undocumented, indocumentado. Following the literature (e.g. Burchardi, Chaney, and Hassan 2018), we take a simple sum of search intensity across all search terms and normalize it by search terms that are popular in the Hispanic community, such as "deportes" (sports) and "telenovelas" (soap operas). This normalization accounts for differential access to the internet for Hispanics that may vary across geographic units.

\section{B. Empirical Framework}

Our triple-differences methodology exploits the staggered roll-out of SC activation across counties as well as the disproportionate impact of SC on Hispanics within counties. Specifically, we estimate the change in pre- versus post-SC activation differences in safety net take-up by race/ethnicity in counties that have activated compared to counties that have not yet activated.

Using repeated county-level cross-sectional data in the ACS, as well as household-level panel data from the PSID, we estimate the following specification 29

$$
\begin{array}{r}
Y_{r c s t}=\alpha+\beta_{1} I_{c t}^{p o s t}+\beta_{2}\left(I_{r}^{H} \cdot I_{c t}^{p o s t}\right)+\beta_{3}\left(I_{r}^{B} \cdot I_{c t}^{\text {post }}\right)+\Omega^{\prime} X_{r c s t}+\mu_{c} \cdot I_{t}^{M o r t o n}+\delta_{s t}+\theta_{r s}+\kappa_{r t} \\
+\Gamma_{1}^{\prime} X_{c s t}+\Gamma_{2}^{\prime}\left(X_{c s t} \cdot I_{r}^{B}\right)+\Gamma_{3}^{\prime}\left(X_{c s t} \cdot I_{r}^{H}\right)+\epsilon_{r c s t}
\end{array}
$$

where $r$ is race/ethnicity, $c$ is county, $s$ is state, and $t$ is year. $Y_{r c s t}$ is the outcome of interest. $Y_{r c s t}$ is the share food stamp or SSI take-up among our sample. In all specifications, we exclude border counties since enforcement activities began in those counties early and selection could have played a role in activation (see Cox and Miles 2014), as well as Massachusetts, New York, and Illinois as these states resisted the activation of SC and attempted to opt-out. We require counties to have at least one known offense per year, since detainers under SC could not have been issued otherwise, and to have at least one respondent from each race group. Our final sample includes 2,759 unique counties from the ACS and 2,260 unique household heads from the PSID.

In the specification above, $I_{r}^{H}$ and $I_{r}^{B}$ are indicators for Hispanic ethnicity and non-Hispanic blacks, respectively. The omitted category is non-Hispanic whites. $I_{c t}^{\text {post }}$ is an indicator equal to one in all county-years after the activation of SC. Almost all counties activated between 2008 to 2013, with the majority of counties activating between 2010 to 2012. $X_{r c s t}$ includes average log poverty rate, number of children, the share citizen, and the employment rate that vary across race, county, and time. We control for these characteristics as they are direct determinants of food stamp or SSI eligibility.

\footnotetext{
${ }^{29}$ We write the equation at the county-level using the ACS data but note the differences for the PSID.
} 
The Great Recession differentially impacted minority-headed households. For instance, white families' wealth fell 26 percent during the Great Recession, while the wealth of black families and Hispanic families fell by 48 and 44 percent, respectively (McKernan et al. 2014). These differential wealth effects may have affected food stamp and SSI take-up by race and ethnicity (Flores-Lagunes et al. 2018). We account for this possibility by explicitly including race/ethnicity-specific state-level employment changes during the Great Recession in $X_{\text {rcst }}$.

State-by-year fixed effects $\left(\delta_{s t}\right)$ are included in our preferred specification to capture statespecific policies or economic shocks that might influence take-up, such as the enactment of state omnibus immigration bills or mandated use of E-Verify to check the work authorization of new hires (Amuedo-Dorantes and Arenas-Arroyo 2017). Such fixed effects also account for differential state-level effects of federal immigration reforms. We include state-by-race/ethnicity fixed effects $\left(\theta_{r s}\right)$ to control for attitudes and policies in each state that differentially affect minority groups. Race-by-year fixed effects $\left(\kappa_{r t}\right)$ non-parametrically capture yearly shocks that differentially affect different racial groups, such as changes in economic conditions. Furthermore, we include county fixed effects $\left(\mu_{c}\right)$ and their interaction with an indicator for post-Morton Memo $\left(I_{t}^{\text {Morton }}\right)$ to capture unobserved county-level factors that affect take-up differentially before and after the 2011 Morton Memo which clarified that county participation in SC was not optional.

Finally, we account for other county-level controls, $X_{c s t}$, that are not publicly available disaggregated by race at the county-level, but which have been shown to have differential effects on minority populations, such as crime. Crime statistics are generally not available at the race-countyyear level but crime disproportionately impacts minority communities (Sampson and Lauritsen 1997, Anwar and Fang 2006, Antonovics and Knight 2009). To allow for these differences, we interact race/ethnicity indicators with the log number of offenses known to law enforcement (Kochhar, Fry, and Taylor 2011; McKernan et al. 2014). Our specification for the PSID is similar to Equation 2. The outcome is an indicator for take-up of food stamps or SSI by individuals in household $i$. In the PSID data, household-level controls, $X_{i r c s t}$, include demographic characteristics on the head of household, including number of children, employment status, and log poverty in the past year.

For the ACS data, we weight all regressions by the total population in the relevant race-county cell 30 To obtain a similar population-weighted estimate in the PSID, we include all individuals from each household and use PSID provided sample weights. We explore the robustness of our results to alternative weighting schemes in Section VII. Standard errors are clustered at the county level.

To measure the spillover (indirect) effects of deportation fear, in both ACS and PSID surveys, we restrict our sample to citizen heads of households, individuals who are not eligible for deportation. We also restrict the sample to those with less than a high school degree as this represents a socioeconomic group that likely meets the income and asset requirements for safety net programs and is more likely to be connected to unauthorized individuals 31

\footnotetext{
${ }^{30}$ On footnote 17 of pg. 312, Solon, Haider, and Wooldridge (2015) clarify that this weighting will only perfectly identify a population average partial treatment effect when the model is fully saturated.

${ }^{31}$ Authors' own calculations from the ACS show that the prevalence of mixed-status families is much higher among
} 
The coefficient of interest in Equation 2 is $\beta_{2}$, which estimates the impact of SC activation on outcomes of Hispanic households relative to non-Hispanic white households, compared to counties that have not yet activated. $\beta_{3}$ serves as a placebo test, capturing the effect of $\mathrm{SC}$ on black households relative to non-Hispanic white households in counties that have activated versus those that have not yet activated.

We also estimate an event study specification, interacting $I_{r}^{H}$ and $I_{r}^{B}$ with a series of time dummies for each period, relative to the omitted year prior to SC activation. The data include sufficient observations to estimate up to five time indicators pre-SC and four time indicators postSC:

$$
\begin{gathered}
Y_{r c s t}=\alpha+\sum_{n \neq-1} \beta_{1}^{n}\left(I_{c, t=n}\right)+\sum_{n \neq-1} \beta_{2}^{n}\left(I_{r}^{H} \cdot I_{c, t=n}\right)+\sum_{n \neq-1} \beta_{3}^{n}\left(I_{r}^{B} \cdot I_{c, t=n}\right)+\Omega^{\prime} X_{r c s t} \\
\quad+\mu_{c} \cdot I_{t}^{\text {Morton }}+\delta_{s t}+\theta_{r s}+\kappa_{r t}+\Gamma_{1}^{\prime} X_{c s t}+\Gamma_{2}^{\prime}\left(X_{c s t} \cdot I_{r}^{B}\right)+\Gamma_{3}^{\prime}\left(X_{c s t} \cdot I_{r}^{H}\right)+\epsilon_{r c s t} .
\end{gathered}
$$

In this specification, $I_{c, t=n}$ is in indicator for each period (other than the year prior to activation $t=-1$ ), such that the $\beta_{2}^{n}$ coefficients trace the take-up of food stamps for Hispanics in the years before and after SC activation relative to non-Hispanic whites ${ }^{32}$ Similarly, each $\beta_{3}^{n}$ coefficient traces the take-up of food stamps for blacks relative to non-Hispanic whites before and after activation. With this specification, one would expect to see a shift post-activation specifically for Hispanic households, and not black or white households, if we are measuring the causal effect of SC.

Identification: The identification assumption underlying our triple-differences approach is that there are no contemporaneous shocks associated with the activation of SC within a county that only affect Hispanic households relative to white households, leaving the black-white gap unchanged. In other words, we assume that any differences in our outcome variables of interest for Hispanic versus white households would have evolved smoothly absent SC activation, conditional on our set of fixed effects and controls.

In addition to testing for pre-trends in the event study analysis, we probe the identifying assumption in three ways. First, we test for pre-SC balance in our covariates and outcomes of interest between Hispanics and non-Hispanic whites across SC-activation groups in the spirit of our main specification in Equation 2. Specifically, we regress the mean Hispanic-white difference for each dependent variable on fixed effects for each activation year group, state fixed effects, log crime, and the respective black-white difference. Standards errors are clustered at the county level. In column 1 of Table 1, we present F-statistics from a test of the joint significance of the activation year group fixed effects. Corresponding p-values from these joint F-tests are presented in column 2 of Table 1. In terms of mean level differences, we find minimal evidence of significant differences across each activation group. Most importantly, we find that there are no significant differences in changes in Hispanic-white outcomes in the pre-SC period across each activation group. These results support

households where the head has less than a high school degree compared to more educated heads.

${ }^{32}$ Leads before five years and lags after four years are coded with the first and last groups, respectively, following McCrary (2007) among others. 
the assertion that the roll-out of SC was not correlated with pre-trends in the differential take-up of safety net programs across groups 33 Second, we test for balance by estimating our baseline specification in Equation 2 where our dependent variables are county-level demographic controls. Results are presented in Table 6 and we can reject that SC activation affected demographic characteristics differentially for Hispanics relative to whites, with a joint F-test for all demographic controls yielding a p-value of 0.99 .

Third, we implement a permutation test where we limit our data to pre-activation years and randomly permute a "pseudo" SC activation year for each county, ensuring that there is at least one year of data pre- and post-"pseudo" activation year. Using these randomly permuted activation years, we then estimate our baseline specification, Equation 2, repeating this procedure 500 times. In Appendix Figure A5, we present the empirical distribution of these placebo effects for $\beta_{2}$, finding that our actual treatment effects for food stamps and SSI are larger (in absolute value) than 98 to 96 percent of our placebo estimates, respectively. These results suggest that SC activation had a large and atypical effect on outcomes for Hispanic households.

Predicted SC Activation: Despite the fact that our triple-differences design does not rely only on the simple pre- versus post-SC activation differences across counties, it is important to understand the factors that affected the timing of SC activation since non-random timing could still introduce bias. For instance, if SC preferentially activated in locations where criminal activity among the unauthorized was on the rise, and such activity decreases program participation, early activators could have seen a Hispanic-specific decline in safety net take-up regardless of SC, leading to overestimates of $\beta_{2}$ in our main specification (Equation 2). On the other hand, if locations that activated early were routine targets of immigration enforcement (such as locations close to the Mexican border), Hispanics in these areas may be relatively insensitive to changes in enforcement and thus exhibit small decreases in safety net take-up, leading us to underestimate $\beta_{2}$ in our main specification.

To further understand the timing of SC activation, Figure 2 presents maps that show the timing of SC activation across counties, revealing that border counties were the earliest places to activate. These findings are consistent with Cox and Miles (2014), who find that SC activation was not related to crime - though the purported goal of the program was to remove criminal aliens - rather, earlier activation was positively correlated with proximity to the border, the presence of a $287(\mathrm{~g})$ agreement, and the percent Hispanic population.

We take several steps to reduce selection bias that might be generated by the non-random timing of SC activation. First, we exclude border areas and three states that actively resisted $\mathrm{SC}$ implementation from our analysis since they might be unique in several ways related to both immigration enforcement and program participation. Second, we include county interacted with time to account for features of a county that may affect timing of activation. Third, in robustness checks described below, we explicitly control for the percent of households that are Hispanic at

\footnotetext{
${ }^{33}$ Goodman-Bacon (2018a) suggests an alternative balance test using novel weights when there are many timing groups and the F-test is underpowered, conditions unlikely to hold in our context.
} 
the county-year level using data from the ACS. Fourth, we review the related literature on SC and official ICE documentation to identify the criteria that affected roll-out timing. Based on our review of these documents, discussed in more detail in the Online Appendix, we identify four criteria that likely affected when a particular county would activate: (1) estimated number of non-citizens, (2) the distance from the Mexican border, (3) crime rates, and (4) prior county relationships with ICE as proxied by the presence of a $287(\mathrm{~g})$ agreement. We use these criteria and their high-level interactions in a cross-section to predict activation year. Figure 3 presents maps that show the timing of predicted SC activation across counties.

In robustness checks, we explore the reduced form relationship between predicted activation and safety net take-up, controlling for our preferred set of fixed effects and baseline controls. We note that variation in predicted activation year is driven by high-level interactions between the four criteria, generating plausibly exogenous timing of SC activation. We find nearly identical results when we use predicted activation compared to actual activation (see Section VI) ${ }^{34}$

\section{Measurement}

Measurement of Citizenship: A generic concern with research on immigration enforcement is that enforcement could alter responses to survey questions regarding citizenship status. While falsely answering a question on a required government survey is punishable by a fine of up to $\$ 10,000$, changes in reporting behavior could compromise our analysis if SC led to missing or misleading survey responses. We show this is not a concern in practice for five reasons. First, based on a recent paper from the Census which links administrative records (AR) on citizenship status from Social Security files to the ACS using personal identification keys (Brown et al. 2018), Hispanics are actually less inclined than other groups to mis-represent citizenship on the ACS and our identification relies on across-group comparisons. Moreover, the proportion of AR Hispanic non-citizens reported as ACS citizens has been steady over the last decade 35

Second, since most misrepresentation of citizenship occurs among foreign-born individuals who have recently moved to the United States, Census researchers classify those who report being born in the United States but missing citizenship status in the AR records as citizens. Thus, for our main ACS sample, we adopt Brown et al.'s (2018) approach and classify individuals as citizens only if they were born in the United States or are naturalized citizens who have been in the country for at least a decade. Furthermore, because AR non-citizens are less likely to respond to the ACS citizen question, we classify all individuals who fail to respond to the citizenship question as noncitizens and exclude them from our sample ${ }^{36}$ In our PSID sample (where citizenship is not asked), we similarly classify individuals as citizens if they grew up in the United States or if their mother

\footnotetext{
${ }^{34}$ In unreported results, we also follow a different, but related approach in Burgess and Pande (2005) and instrument for actual activation using each of the four criteria listed above interacted with a linear time trend. While there is not a strong first-stage relationship $($ F-statistic $=3.7)$ under this approach, we find qualitatively similar estimates.

${ }^{35}$ See Appendix Table A8 Panels (A) to (C) in Brown et al. (2018).

${ }^{36}$ Brown et al. (2018) find that $5 \%$ of AR Hispanic non-citizens skip the citizen question compared to $2 \%$ of AR Hispanic citizens, a pattern that is consistent across other demographic groups.
} 
and father were both born in the United States. This approach yields a conservative sample of individuals who are most likely to be AR citizens.

Third, we cross-validate our classification of naturalized citizens using state-year administrative data from DHS. The correlation between our ACS count of naturalized citizens and the DHS count is 0.94 (see Appendix Figure A6) ${ }^{37}$ Fourth, to directly address the concern that there are changes in reporting of naturalization status and natality, we test and find no evidence that $\mathrm{SC}$ activation affected the share of Hispanics who are U.S. citizens in the ACS (see Section VII). Fifth, we take advantage of the panel nature of the PSID and rule out that Hispanic household heads changed their responses to race and natality questions in the aftermath of SC.

Measurement of Program Take-up: In addition to measurement error associated with reporting of citizenship, individuals may be fearful of reporting safety net participation. Meyer, Mittag, and Goerge (2018) emphasize that survey data often does not comport with administrative records on program participation, with false negatives and positives both possible, though the former is generally found to be much more important than the latter. Since our main specification relies on the difference between Hispanic and white-headed households, under-reporting will bias our estimates if it changes over time in relationship to SC for one particular group. A prominent explanation for false negatives among Hispanic households is fear related to immigration concerns (Brown 2015).

In our context, fear could lead to measurement error in the outcome variable that is correlated with the introduction of SC ${ }^{38}$ To the extent the implementation of SC heightens deportation fear, our estimates therefore capture both the actual reduction in safety net take-up as well as an increase in false negatives. Although both effects are of interest, they have very different policy implications.

To gauge whether under-reporting of take-up responds to SC, we follow the literature and compare administrative SNAP data where available with survey estimates over time. We use administrative SNAP data from a group of states that provide participation information disaggregated by race and year (California, North Dakota, Oklahoma, Minnesota) ${ }^{39}$ Similar to other scholars, we find that ACS estimates of food stamp take-up are generally lower than available official yearly state-level estimates. Importantly, however, the gap between survey and administrative take-up does not change post SC for Hispanics or other racial/ethnic groups (see Appendix Table A2). We also find using our triple-differences specification that the gap between survey and administrative data participation for Hispanics relative to non-Hispanic whites does not change significantly post-SC (column 4 of Appendix Table A2). These findings suggest that SC had limited effects on reporting of program participation.

\footnotetext{
${ }^{37}$ In unreported results, we also find that the gap between our ACS and DHS counts does not change post SCactivation.

${ }^{38}$ Assuming reported participation is less than true participation (participation $=$ participation - fear $)$, then $\hat{\beta}=\beta-\frac{\operatorname{cov}(S C, \text { fear })}{\operatorname{var}(S C)}$ where $\operatorname{cov}(S C$, fear $)$ is likely positive.

${ }^{39}$ Official disaggregated estimates of take-up of SSI by race/ethnicity are unavailable. See https://www.ssa.gov/ policy/docs/rsnotes/rsn2016-01.html.
} 


\section{Results}

Figure 4 presents our main event study estimates of SC activation on food stamp take-up (Panel A) and SSI take-up (Panel B) for non-Hispanic whites, non-Hispanic blacks, and Hispanics using the ACS data, as described in Equation 3 . For both non-Hispanic whites and blacks, there is no noticeable break in the relative flatness of take-up of either safety net program in the five years pre- and four years post-SC activation. In sharp contrast, coefficients on the interaction of time to SC and Hispanic are indistinguishable from zero in the years leading up to activation, but then demonstrate a level shift post-activation, with Hispanic heads greatly decreasing their take up of both food stamps and SSI over time. Specifically, by four years post-activation, Hispanic households reduce take-up of food stamps by 5.6 percentage points relative to non-Hispanic whites, a 26 percent decrease from the pre-period Hispanic mean of 21.8 percent. Similarly, by four years post-activation, Hispanic households reduce their take-up of SSI by 3.8 percentage points relative to non-Hispanic whites, a 72 percent decrease from the pre-period Hispanic mean of 5.3 percent. Similar event studies comparing Hispanics to all non-Hispanics (both white and black) are shown in Figure 5.

Table 2 presents our main results on safety net take-up in the ACS data. Columns 1 and 2 present results for food stamp take-up and columns 3 and 4 report results for SSI take-up. In column 1, we find that after SC activation, Hispanic citizen heads of household reduce their take-up of food stamps by 2.1 percentage points relative to non-Hispanics, a ten percent decrease from the pre-period Hispanic mean. In column 2, we report the same specification as column 1 but add an interaction between our black indicator and post-SC indicator. Our main results are virtually unchanged and we also find a small and insignificant black coefficient post-SC, indicating that SC did not similarly affect the behavior of minority groups less likely to be affected by immigration enforcement. In column 3, we find that Hispanic citizen heads of household reduce their take-up of SSI by 1.6 percentage points after SC activation relative to non-Hispanics, a 30 percent decrease from the pre-period Hispanic mean. Again, these results remain stable with the inclusion of an interaction between our black interacted with post-SC indicator, which is small and statistically insignificant (column 4).

Our main findings are also qualitatively similar using the PSID data, shown in Table 3 . Column 1 and 2 present results for food stamp take-up and columns 3 and 4 present analogous results for SSI take-up. In column 1, we find that after SC activation, Hispanic citizen households reduce their take-up of food stamps by 13.8 percentage points relative to non-Hispanic whites, a 40 percent decrease from the pre-period Hispanic mean of 34.1 percent. We also find reductions in Hispanic citizen households' take-up of SSI after SC activation relative to non-Hispanics. In our full sample, Hispanic households reduce SSI take-up by 1.9 percentage points after SC (column 3), a 50 percent decrease from the pre-period Hispanic mean of 4.0 percent. While the results for food stamps and SSI fail to reach conventional levels of statistical significance in the PSID, likely due to the small sample size, our PSID and ACS estimates are not statistically different from each other 40

\footnotetext{
${ }^{40}$ There are several reasons why the magnitudes of our estimates differ slightly between the PSID and ACS samples. First, after our sample restrictions, the PSID covers only 628 counties versus 2,759 in the ACS and differentially covers
} 
In columns 2 and 4 of Table 3 , we find evidence that these decreases in both food stamp and SSI take-up are driven primarily by households that had previously taken up the benefits. We return to these results on prior users in Section VII.B when we explore potential mechanisms explaining our results. Notably, across all our specifications and samples in Table 2 and Table 3 , we find evidence not only of differential decreases in food stamp and SSI take-up for Hispanics, but absolute decreases for Hispanic households following SC.

Table 4 presents several robustness checks of our main results for both food stamp take-up (Panel A) and SSI take-up (Panel B). Column 1 presents results excluding controls for race-by-state changes in employment during the Great Recession. Column 2 controls for a full set of county-byyear fixed effects with corresponding event studies shown in Appendix Figure A7. Column 3 presents results using predicted activation year rather than actual activation year. Column 4 presents results comparing Hispanics to all non-Hispanics (white and black). Column 5 presents results controlling for pre-activation trends in program take-up following the approach in Freyaldenhoven, Hansen, and Shapiro (forthcoming). Column 6 presents results on a sample of citizen household heads with less than a college degree. Across all alternative specifications and samples, we continue to find economically meaningful and statistically significant reductions in safety net take-up for Hispanic households relative to non-Hispanics after SC activation.

Additional robustness checks are presented in Appendix Table A3. In column 1, we estimate our main results in the ACS on a sample of counties that matches the PSID in terms of preperiod take-up rates for Hispanics, finding that our main ACS estimates from Table 2 are nearly identical in magnitude to our PSID estimates from Table 3 in this matched sample. In column 2, we consider the fact that food stamp participation may be decided by females within a household. We find very similar results using a sample of citizen female heads of household or female spouses. We also find similar results when we exclude citizen heads of households with mixed-status family members (column 3). These results suggest that our main findings capture a true spillover effect of deportation fear. In column 4, we find that our results are qualitatively similar to dropping New York, Los Angeles, Miami, Houston, and Chicago from our sample, cities that have the highest number of Hispanic immigrants.

In column 5 of Appendix Table A3, we relax the assumption that Hispanics are only affected by enforcement in their county by including a spatial lag in SC activation, weighting each county's enforcement with an exponential spatial weight matrix that places lower weight on farther locations. Again, we find that our results are virtually identical with the inclusion of a spatial lag, suggesting that Hispanic households are most responsive to enforcement within their own county 41 In column 6, we estimate our results at the PUMA rather than county level to address concerns about measurement error associated with apportioning ACS PUMA-level attributes to the county level.

large states like California and Texas, whereas the ACS is nationally representative. Second, as discussed earlier, the PSID specifically added a large wave of immigrant families to the survey in 1997 and thus likely over-samples immigrant families relative to the ACS. Third, reported food stamp usage is much higher in the PSID versus ACS sample. When we select an ACS sample that matches the PSID in pre-period mean take-up for Hispanics, we find nearly identical magnitudes of our estimates (see column 1 of Appendix Table A3.)

${ }^{41}$ The coefficient on the spatial lag is small and not statistically significant. 
We find similar results when we assign the earliest SC activation date to each PUMA, providing reassurance that our results are not driven by the process of PUMA to county apportionment.

In column 7, we present results from our main specification where for treated counties that activate in a particular year, we define control counties as those that activate more than two years in the future, following Deshpande and Li (forthcoming) ${ }^{42}$ Finally, column 8 presents results for a sample of citizen households where the head has some college or more, a sample that has much lower participation in safety net programs and lower connectedness to non-citizens compared to our preferred sample. We find that our estimates are much smaller in magnitude in this alternative sample, suggesting that the effect of SC on program take-up is most concentrated among our fragile connected sample.

Finally, Appendix Table A4 explores alternative weighting schemes and alternative controls. For example, our results are qualitatively similar when we do not use population weights (column 1), and coupled with the results from Appendix Table A3 column 4, suggest the findings are not driven by a few populous counties. Our results are also robust to including one observation for each family member in a citizen head household in the ACS, thus capturing the effect of SC at the individual level rather than household level (column 2). Our results are also very similar controlling for the share of a county that is Hispanic (column 3) and for the number of Hispanic non-citizens in each county (column 4), addressing concerns that our results are driven by flows of program-eligible Hispanics that are correlated with the timing of SC activation.

\section{Mechanisms}

In this section, we explore potential mechanisms for our results. We begin by examining the role fear may have played before turning to other postulated mechanisms, including information and compositional changes. We also consider the role of changes in reporting behavior.

\section{A. Fear}

$\mathrm{SC}$ increased the number of detainers issued and forcible removals from the interior, which may have increased deportation fear. Indeed, Pew Research Center survey data demonstrate a positive correlation between respondents knowing someone who was detained and being fearful of the same fate befalling a family member or close contact (see Figure 6) 43 This relationship has also been

\footnotetext{
${ }^{42}$ As pointed out in several recent papers on staggered adoption difference-in-differences research designs (e.g. de Chaisemartin and D'Haultfoeuille (2018) and Goodman-Bacon (2018a)) the two-way fixed effects estimator is a weighted average of treatment effects, where some of the weights can be negative. Negative weights occur in situations when the treatment effect is heterogeneous over time. de Chaisemartin and D'Haultfoeuille (2018) develop an estimator which is valid under these conditions: the Wald-TC, which is the LATE for the switchers (i.e. entities that change treatment status, compared to the yet to be treated) and provide a Stata command for this estimator in de Chaisemartin et al. (forthcoming). This approach is similar in spirit to that of Deshpande and Li (forthcoming). We compute the Wald-TC for both safety net outcomes (e.g. SNAP and SSI) across each demographic group. The Wald-TC is consistently negative and near to our triple difference estimates for the Hispanic sample. It is generally near zero for the non-Hispanic black and white samples with the exception of SSI among African-Americans.

${ }^{43}$ Pew asked the following question in 2010 and 2013: "Regardless of your own immigration or citizenship status, how much, if at all, do you worry that you, a family member, or a close friend could be deported? Would you say
} 
described in anecdotal evidence with regards to SC activation, as detailed in the 2011 Task Force Review on Secure Communities (HSAC Task Force 2011).

To formally explore whether fear may be contributing to the findings reported above, we present six analyses. First, we use the Google Trends data on deportation-related search terms in English and Spanish available at the DMA media market level to test whether such searches increase in the years post-SC activation. We condition on year fixed effects, log neutral searches (such as popular Hispanic actors/musicians/politicians), and DMA media market fixed effects, clustering standard errors at the DMA media market level. We find no discernible pre-trend, but a sharp 25 percent increase in normalized deportation-related searches immediately following SC activation (see Figure 7), consistent with at least an awareness of the SC program if not fear of its potential consequences ${ }^{44}$

Second, immigration enforcement activity directed against those who have committed minor offenses has also been argued to heighten fear and impede participation in government-associated activities, as SC led to substantial increases in deportations for individuals arrested for misdemeanors such as public drunkenness or jaywalking (HSAC Task Force 2011). Our second analysis, reported in columns 1 and 5 of Table 5 , finds that the effect of SC on both food stamp and SSI takeup is larger in counties where there is a higher proportion of non-violent detainers (often issued for misdemeanor offenses) to all violent (often issued for assault or murder) plus non-violent detainers. In counties where that proportion is one (corresponding to the 90th percentile of the distribution), Hispanic households reduce their take-up of food stamps and SSI by an additional 0.06 and 0.03 percentage points, respectively.

Third, using the Pew data, we test whether reductions in program participation are higher in areas with increasing deportation fear measured at the Census division level (the finest geography available in 2013). We find that a one standard deviation increase in fear is associated with an additional 1.7 percentage point decline in food stamp take-up (column 2) and a 0.9 percentage point decline in SSI take-up among Hispanics after SC activation (column 6).

Fourth, we explore the role of sanctuary cities and counties. As described previously, sanctuary cities share in common their restrictions on how much local governments cooperate with ICE requests to detain immigrants. If fear explains our findings, then Hispanic households in sanctuary cities should have less fear and thus exhibit a lower response to SC. In columns 3 and 7, we interact our Hispanic and post-SC indicator with an indicator for an active sanctuary city policy during the period of SC activation. We find that almost all of our main effects for food stamp take-up are driven by locations with no sanctuary policy. Specifically, we find a significant and positive effect of SC activation on Hispanics in sanctuary cities relative to non-sanctuary cities, such that

that you worry a lot, some, not much, or not at all?" From this question, we define individuals who respond that they worry a lot or some as being "fearful" and limit the sample to Hispanic citizen respondents so as to more nearly approximate spillover effects. We also limit the sample to states with at least five respondents. In 2010, Pew also asked a specific question on knowledge of detention/deportation: "Do you personally know someone who has been deported or detained by the federal government for immigration reasons in the last 12 months?" We use the 2010 data in Figure 6

${ }^{44}$ In unreported results, we find qualitatively similar estimates on program take-up if we estimate our results at the DMA media market level instead of the county level. 
SC activation has a net null effect on Hispanics in sanctuary jurisdictions 45 Appendix Figure A8 presents corresponding event study estimates of the differential effect of SC activation on program take-up in sanctuary versus non-sanctuary jurisdictions.

Fifth, we explore the idea that if fear is an explanatory factor, counties with a higher share of Hispanics that face zero to minimal deportation risk should be less responsive to SC activation. In particular, we measure the share of Hispanics in a county that are Puerto Rican or Cuban, given that Puerto Ricans have citizenship status and thus cannot be deported, and Cubans are more likely to have political refugee status and thus face a lower risk of deportation. In columns 4 and 8, we find that Hispanics in counties with a ten percent higher share of Puerto Ricans and Cubans experience significantly smaller reductions in both food stamp (0.3 percentage points) and SSI (0.4 percentage points) take-up.

Sixth, and finally, we explore the hypothesis that households and communities with more mixing or exposure between non-citizen and citizen Hispanics should be more influenced by SC activation, as suggested by our model and qualitative findings. Exposure to non-citizens is highly relevant for Hispanic communities because Hispanics live in ethnically homogeneous neighborhoods, with Hispanic segregation generally increasing over the past decade 46

In Figure 8, we present a series of results on take-up based on the "intensity" of treatment. Compared to our main coefficient in our preferred specification, reductions in take-up are relatively larger in counties with a higher share of Hispanic households that are mixed-status. Specifically, Hispanic households from counties with a ten percent higher share of mixed-status households decrease take-up of food stamps and SSI by an additional 0.1 and 0.3 percentage points after SC activation, respectively. Take-up is further dampened in counties with a higher share of Hispanics that are non-citizens. Hispanic households from counties with a ten percent higher share of Hispanics who are non-citizens decrease take-up of food stamps by an additional 0.5 percentage points and decrease take-up of SSI by an additional 0.5 percentage points post-SC.

Finally, we use share mixed at the household level interacted with share non-citizen at the county level as a measure of exposure to relevant information. The higher the share non-citizen in a county, the easier information could spread regarding the heightened risk of deportation under $\mathrm{SC}$ (see Figure 6). The greater the share of mixed-status households in the area, the more salient that information is for take-up decisions. This "exposure index" thus captures the probability that a mixed-status household is randomly exposed to a Hispanic non-citizen in a county. A ten percent increase in the exposure index decreases food stamps by an additional 1.1 percentage points and SSI by an additional 0.9 percentage points after the activation of SC.

Taken together, these six findings suggest that fear of deportation is a likely explanatory mechanism 47

\footnotetext{
${ }^{45}$ See the Online Appendix for institutional details of sanctuary cities.

${ }^{46}$ See https://www.brookings.edu/opinions/census-data-blacks-and-hispanics-take-different-segregation-paths / Mixed-status families are also much more common among Hispanic households relative to other groups. In the ACS data, we find that 18 percent of Hispanics households have at least one non-citizen Hispanic, compared to 0.20 percent of white households and 0.04 percent of black households.

${ }^{47} \mathrm{~A}$ related explanation is the role of legitimacy, or the theory that individuals cooperate or engage with legal
} 


\section{B. Information}

We next consider an alternative mechanism - the role of information. Information sharing might explain our findings to the extent that individuals rely on other people from their networks about information on public programs, with prior work suggesting that take-up of food stamps and other programs increases with greater information on eligibility and outreach (see Daponte et al. 1999 and Aizer 2003). In particular, information might be salient for immigrant communities to the extent that there is greater confusion or uncertainty about eligibility.

In our context, greater immigration enforcement may reduce take-up of public programs among citizen Hispanic households if they lose access to information as non-citizen co-ethnics in their networks reduce take-up. We partially test this hypothesis by comparing our estimated effects for Hispanic households that had never previously taken up the relevant public program prior to SC versus Hispanic households that previously took up the program following Aizer and Currie (2004). If a household has previously taken up the program, the household will likely already have information about the program, such as eligibility and how to apply. As a result, if information explains our findings, we would expect to find smaller effects of SC activation for prior use households.

Columns 2 and 4 of Table 3 presents these results in the PSID sample where we limit the sample exclusively to all individuals in households that have taken up food stamps or SSI prior to SC activation, respectively. In our PSID sample, 52 percent of Hispanic households are prior users of food stamps before SC activation and on average, prior users take up food stamps 73 percent of the time before SC activation. In the PSID, 8 percent of Hispanic households are prior users of SSI and take up SSI 49 percent of the time on average before SC activation. We find that the decline in both food stamp and SSI take-up post SC is largely driven by Hispanic heads that have previously taken up these safety net programs. Among prior users, SC activation reduced Hispanic heads of household take-up of food stamps by 49.6 percentage points and take-up of SSI by 112.9 percentage points relative to non-Hispanics. These results suggest that our main findings are unlikely due to Hispanic households being less likely to receive information about public programs as their co-ethnics reduce sign up. This finding, combined with qualitative evidence suggesting that Hispanic families are not renewing benefits, also lessens the likelihood that an explanation like stigma is driving our results.

\section{Compositional Changes}

We also consider the possibility that SC activation may have affected the number or types of Hispanic citizens and households living within a particular county or within the United States, or more subtly, the number or types willing to declare their ethnicity or report program take-up in surveys like the ACS. This line of query is important since the Great Recession affected migration, in general reducing it (Johnson et al. 2016), although immigrants were more sensitive to local

authorities based on their perception of how fairly these authorities deal with members of the public (Tyler 2006). Under this theory, SC may have reduced program participation because it corroded the perceived legitimacy of the federal government in the eyes of Hispanic citizens. However, we find larger effects of SC in areas with more mixed-status households and smaller effects in areas with greater shares of Cubans and Puerto Ricans as described previously, findings that are hard to reconcile with a general theory of legitimacy. 
economic downturns (Cadena and Kovak 2016). While we note that these responses may also be driven by fear, compositional changes in Hispanic survey respondents within a particular county or changes in reporting behavior may lead to a different interpretation of our main findings.

To test this channel, Table 6 presents our main specification in the ACS, where the dependent variables are average race-specific observable characteristics of citizens/households in each county-year, race-specific household weights in each county-year from the ACS, and the percent mixed-status and U.S.-born citizen among Hispanics in each county-year. We find no significant relationship between SC activation and compositional changes in the types of Hispanics relative to non-Hispanics in each county-year in terms of number of children, poverty level, or employment rate (columns 1-3) ${ }_{48}^{48}$ We also find no evidence of differential migration of Hispanics, measured by the share that report moving between states in the past year (column 4) or evidence that household weights from the ACS change differentially for Hispanics relative to other groups after SC activation (column 5). Finally, we find no statistically significant change in the percent of Hispanic mixed-status families or share citizen within a county post-SC activation (columns 6-7).

As another test of whether compositional changes could explain our findings, we predict both food stamp and SSI take-up using our race-specific observable characteristics of citizens/households in each county-year. We then estimate our main specification using predicted take-up as our dependent variable. Appendix Figure A9 presents these results and shows no evidence of significant changes or trend breaks in predicted take-up for Hispanics relative to non-Hispanic whites post-SC activation, in sharp contrast to our main event studies in Figure 4.

\section{Conclusion}

In this study, we test the hypothesis that linkages between citizens and non-citizens reduce safety net participation in the presence of enhanced immigration enforcement activity. Leveraging the roll-out of Secure Communities under the Obama administration, we find that citizen Hispanic Americans are indeed sensitive to such enforcement although they themselves are not at risk of removal - a spillover effect. In particular, we find significant reductions in food stamp and SSI takeup among Hispanic households. We find evidence that our results may be driven by deportation fear rather than lack of benefit information, measurement error, or stigma. Hispanic citizens residing in areas with a higher degree of connectedness with non-citizens, areas with a higher incidence of detainers issued for low-level arrests, and areas with greater increases in deportation fear exhibit larger decreases in take-up in response to SC. In contrast, Hispanic households residing in sanctuary cities and areas with a higher share of Puerto Ricans and Cubans exhibited more muted responses to SC activation.

These findings are particularly relevant given recent immigration policies. For one, the reactivation of SC in 2017 has substantially increased deportations relative to prior years. In contrast

\footnotetext{
${ }^{48}$ Using a differences-in-differences approach, East et al. (2018) find that SC reduced the employment rate of all citizens by 0.5 percent. Our triple-differences approach compares the differential change for Hispanic citizens relative to other groups.
} 
to the operation of SC under the Obama administration, a larger share of deportations under the Trump administration result from arrests for misdemeanor and petty offenses, which may enhance deportation fear. Second, recently proposed changes to the "public charge" determination, a designation that can prevent a non-citizen from adjusting their immigration status to legal permanent resident, could further intensify the spillover effects of fear. In 2018, DHS proposed to substantially expand the definition of a public charge to include any immigrant who "uses or receives one or more public benefits," including both SSI and food stamps (previously exempt from public-charge determination). Moreover, the new proposal contemplates that use of these programs by U.S.-born citizen spouses and children could also count towards non-citizens' use of public assistance, with some estimates suggesting that up to one third of U.S.-born citizens could have their use of public benefits considered in the public-charge determination of a family member (Perreira et al. 2018). Our results suggest that these policy changes could lead to further decreases in sign-up of safety net programs as Hispanic citizens may fear that their participation could jeopardize the chances that a family member obtains legal permanent residency.

Ultimately, our results have several implications on health and well-being for Hispanic households. A back-of-the-envelope calculation based on number of recipients and average benefit size suggests that as a result of SC, Hispanic households forgo over $\$ 212$ million and $\$ 77$ million in food stamp and SSI benefits per year, respectively. Extrapolating from the work of other scholars, families could experience adverse long-run consequences from forgoing benefits in response to stricter immigration enforcement. For example, Hoynes, Schanzenbach, and Almond (2016) show that food stamp take-up reduces the incidence of metabolic syndrome in adulthood, and Tiehen et al. (2012) find that food stamp participation reduced the child poverty rate by 5.6 percent from 2000 to 2009 . Bronchetti et al. (2018) find that higher food stamp purchasing power increases the utilization of preventive medical care for children and reduces days of school missed due to illness. Similarly, Duggan and Kearney (2007) find that child participation in SSI is linked with long-term reductions in child poverty and Deshpande (2016) finds that removing disabled youth from SSI leads to a large decrease in observed lifetime income and exposes youth to greater income volatility. Schmidt, Shore-Sheppard, and Watson (2016) find that SSI program participation leads to a reduction in family food insecurity. These results suggest that reductions in food stamp and SSI usage among Hispanics in response to immigration enforcement could have long-run consequences for health and economic security. Most broadly, our results reveal how the dual role of federal authority as both enforcer and benefactor influences the take-up decisions of vulnerable households, yielding potentially unexpected results for families. 


\section{References}

[1] Aizer, Anna. 2003. "Low Take-Up in Medicaid: Does Outreach Matter and for Whom?" American Economic Review, 93(2): 238-241.

[2] Aizer, Anna, and Janet Currie. 2004. "Networks or Neighborhoods? Correlations in the Use of Publicly-Funded Maternity Care in California." Journal of Public Economics, 88(12): 2573-2585.

[3] Aizer, Anna. 2007. "Public Health Insurance, Program Take-Up, and Child Health." Review of Economics and Statistics, 89(3): 400-415.

[4] Aizer, Anna, Shari Eli, Joseph Ferrie, and Adriana Lleras-Muney. 2016. "The Long-Run Impact of Cash Transfers to Poor Families." American Economic Review, 106(4): 935-971.

[5] Almada, Lorenzo N., and Rusty Tchernis. 2018. "Measuring Effects of SNAP on Obesity at the Intensive Margin." Economics and Human Biology, 31: 150-63.

[6] Almond, Douglas, Hilary W. Hoynes, and Diane Whitmore Schanzenbach. 2011. "Inside the War on Poverty: The Impact of Food Stamps on Birth Outcomes." Review of Economics and Statistics, 93(2): 387-403.

[7] Amuedo-Dorantes, Catalina, Esther Arenas-Arroyo, and Almudena Sevilla. 2018. "Immigration Enforcement and Economic Resources of Children with Likely Unauthorized Parents." Journal of Public Economics, 158: 63-78.

[8] Antonovics, Kate, and Brian Knight. 2009. "A New Look at Racial Profiling: Evidence from the Boston Police Department." Review of Economics and Statistics, 91(1): 163-177.

[9] Anwar, Shamena, and Hanming Fang. 2006. "An Alternative Test of Racial Bias in Motor Vehicle Searches: Theory and Evidence." American Economic Review, 96(1): 127-151.

[10] Asad, Asad L., and Matthew Clair. 2018. "Racialized Legal Status as a Social Determinant of Health." Social Science and Medicine, 199: 19-28.

[11] Ashenfelter, Orley. 1983. "Determining Participation in Income-Tested Social Programs." Journal of the American Statistical Association, 78(383): 517-525.

[12] Bean, Frank, Susan Brown, and James Bachmeier. 2015. Parents Without Papers: The Progress and Pitfalls of Mexican American Integration. New York, NY: Russell Sage Foundation.

[13] Becker, Gary S., and Yona Rubinstein. 2011. "Fear and the Response to Terrorism: An Economic Analysis." CEP Discussion Paper, 1079.

[14] Bertrand, Marianne, Erzo F. P. Luttmer, and Sendhil Mullainathan. 2000. "Network Effects and Welfare Cultures." Quarterly Journal of Economics, 115(3): 1019-1055.

[15] Besley, Timothy, and Stephen Coate. 1992. "Understanding Welfare Stigma: Taxpayer Resentment and Statistical Discrimination." Journal of Public Economics, 48(2): 165-183.

[16] Bhargava, Saurabh, and Dayanand Manoli. 2015. "Psychological Frictions and the Incomplete Take-Up of Social Benefits: Evidence from an IRS Field Experiment." American Economic Review, 105(11): 3489-3529.

[17] Bitler, Marianne, and Hilary Hoynes. 2015. "Heterogeneity in the Impact of Economic Cycles and the Great Recession: Effects within and across the Income Distribution." American Economic Review: Papers and Proceedings, 105 (5): 154-160. 
[18] Bohn, Sarah, Magnus Lofstrom, and Steven Raphael. 2014. "Did the 2007 Legal Arizona Workers Act Reduce the State's Unauthorized Immigrant Population?" Review of Economics and Statistics, 96(2): 258-269.

[19] Borjas, George J. 1992. "Ethnic Capital and Intergenerational Mobility." Quarterly Journal of Economics, 107(1): 409-439.

[20] Borjas, George J., and Lynette Hilton. 1996. "Immigration and the Welfare State: Immigrant Participation in Means-Tested Entitlement Programs." Quarterly Journal of Economics, 111(2): 575-604.

[21] Borjas, George J. 2017. "The Labor Supply of Undocumented Immigrants." Labour Economics, 46:1-13.

[22] Bronchetti, Erin T., Garret Christensen, and Hilary W. Hoynes. 2018. "Local Food Prices, SNAP Purchasing Power, and Child Health." NBER Working Paper, 24762.

[23] Brown, Anna. 2015. "The Unique Challenges of Surveying U.S. Latinos." Washington, D.C.: Pew Research Center.

[24] Brown, J. David, Misty L. Heggeness, Suzanne M. Dorinski, and Lawrence Warren. 2018. "Understanding the Quality of Alternative Citizenship Data Sources for the 2020 Census." CES Research Paper, 18-38.

[25] Browning, Martin, Pierre-André Chiappori, and Valérie Lechene. 2006. "Collective and Unitary Models: A Clarification." Review of Economics of the Household, 4(1): 5-14.

[26] Burchardi, Konrad B., Thomas Chaney, and Tarek A. Hassan. 2018. "Migrants, Ancestors, and Foreign Investments." Review of Economic Studies, 0: 1-39.

[27] Burgess, Robin, and Rohini Pande. 2005. "Do Rural Banks Matter? Evidence from the Indian Social Banking Experiment." American Economic Review, 95(3): 780-795.

[28] Cadena, Brian C., and Brian K. Kovak. 2016. "Immigrants Equilibrate Local Labor Markets: Evidence from the Great Recession." American Economic Journal: Applied Economics, 8(1): 257-290.

[29] Cascio, Elizabeth U., and Ethan G. Lewis. 2019. "Distributing the Green (Cards): Permanent Residency and Personal Income Taxes after the Immigration Reform and Control Act of 1986." Journal of Public Economics 172: 135-150.

[30] Coleman-Jensen, Alisha, Christian A. Gregory, and Anita Singh. 2014. "Household Food Security in the United States in 2013." United States Department of Agriculture, Economic Research Report Number 173.

[31] Congressional Budget Office. 2012. "The Supplemental Nutrition Assistance Program." https://www.cbo.gov/publication/43173. Washington, DC: Congressional Budget Office.

[32] Cox, Donald, and Marcel Fafchamps. 2008. "Extended Family and Kinship Networks: Economic Insights and Evolutionary Directions." Handbook of Development Economics, Volume 4.

[33] Cox, Adam B., and Thomas J. Miles. 2013. "Policing Immigration." University of Chicago Law Review, 80(87): 87-136.

[34] Cox, Adam B., and Thomas J. Miles. 2014. "Does Immigration Enforcement Reduce Crime? Evidence from 'Secure Communities'." Journal of Law and Economics, 57(4): 937-973.

[35] Dahl, Gordon B., Andreas Ravndal Kostøl, and Magne Mogstad. 2014. "Family Welfare Cultures." Quarterly Journal of Economics, 129(4): 1711-1752. 
[36] Cruz Nichols, Vanessa, Alana M. W. LeBrón, and Francisco I. Pedraza. 2018. "Spillover Effects: Immigrant Policing and Government Skepticism in Matters of Health for Latinos." Public Administration Review, 78(3): 432-443.

[37] Currie, Janet. 2006. "The Take-Up of Social Benefits." In Alan J. Auerbach, David Card, and John M. Quigley, eds., Public Policy and the Income Distribution, New York: Russell Sage Foundation: $80-148$.

[38] Daponte, Beth O., Seth Sanders, and Lowell Taylor. 1999. "Why Do Low-Income Households Not Use Food Stamps? Evidence from an Experiment." Journal of Human Resources, 34(3): 612-628.

[39] de Chaisemartin, Clement, and Xavier D'Haultfoeuille. 2018. "Two Way Fixed Effects Estimators With Heterogeneous Treatment Effects." Working Paper.

[40] de Chaisemartin, Clement, Xavier D'Haultfoeuille, and Yannick Guyonvarch. forthcoming. "Fuzzy Differences-in-Differences in Stata." Stata Journal.

[41] Daly, Mary, and Richard V. Burkhauser. 2003. "The Supplemental Security Income Program." In The Making of the American Essay, edited by Robert A. Moffitt, 79-139. Chicago: University of Chicago Press.

[42] Deshpande, Manasi. 2016. "Does Welfare Inhibit Success? The Long-Term Effects of Removing Low-Income Youth from the Disability Rolls." American Economic Review, 106(11): 33003330 .

[43] Deshpande, Manasi, and Yue Li. forthcoming. "Who Is Screened Out? Application Costs and the Targeting of Disability Programs." American Economic Journal: Economic Policy.

[44] di Falco, Salvatore, and Erwin Bulte. 2011. "A Dark Side of Social Capital? Kinship, Consumption, and Savings." Journal of Development Studies, 47(8): 1128-1151.

[45] Duggan, Mark, and Melissa S. Kearney. 2007. "The Impact of Child SSI Enrollment on Household Outcomes." Journal of Policy Analysis and Management, 26(4): 861-885.

[46] Duggan, Mark, Melissa S. Kearney, and Stephanie Rennane. 2016. "The Supplemental Security Income (SSI) Program." In Economics of Means-Tested Transfer Programs in the United States, Volume 2, Robert Moffitt, eds. 1-58. Chicago, IL: University of Chicago Press.

[47] East, Chloe. 2018. "The Effect of Food Stamps on Children's Health: Evidence from Immigrants' Changing Eligibility." Journal of Human Resources.

[48] East, Chloe, Philip Luck, Hani Mansour, and Andrea Velasquez. 2018. "The Labor Market Effects of Immigration Enforcement." IZA Discussion Paper, 11486.

[49] Flores-Lagunes, Alfonso, Hugo B. Jales, Judith Liu, and Norbert L. Wilson. 2018. "The Differential Incidence and Severity of Food Insecurity by Racial, Ethnic, and Immigrant Groups over the Great Recession in the United States." American Economic Association Papers and Proceedings, 108: 379-383.

[50] Freyaldenhoven, Simon, Christian Hansen, and Jesse M. Shapiro. forthcoming. "Pre-Event Trends in the Panel Event-Study Design." American Economic Review.

[51] Ganong, Peter, and Jeffrey B. Liebman. 2018. "The Decline, Rebound, and Further Rise in SNAP Enrollment: Disentangling Business Cycle Fluctuations and Policy Changes." American Economic Journal: Economic Policy, 10(4): 153-76.

[52] Goodman-Bacon, Andrew. 2018a. "Difference-in-Differences with Variation in Treatment Timing." NBER Working Paper, 25018. 
[53] Goodman-Bacon, Andrew. 2018b. "Public Insurance and Mortality: Evidence from Medicaid Implementation." Journal of Political Economy, 126(1): 216-262.

[54] Hacker, Karen, Jocelyn Chu, Carolyn Leung, Robert Marra, Alex Pirie, Mohamed Brahimi, Margaret English, Joshua Beckmann, Dolores Acevedo-Garcia, and Robert P. Marlin. 2011. "The Impact of Immigration and Customs Enforcement on Immigrant Health: Perceptions of Immigrants in Everett, Massachusetts, USA." Social Science and Medicine, 73(4): 586594.

[55] Homeland Security Advisory Council Task Force. 2011. "Task Force on Secure Communities Findings and Recommendations." September 2011. https://www.dhs.gov/xlibrary/assets/hsac-task-force-on-secure-communities.pdf

[56] Hoynes, Hilary, Diane Whitmore Schanzenbach, and Douglas Almond. 2016. "Long-Run Impacts of Childhood Access to the Safety Net." American Economic Review, 106(4): 903-934.

[57] Johnson, Kenneth M., Katherine J. Curtis, and David Egan-Robertson. 2016. "How the Great Recession Changed U.S. Migration Patterns." Population Trends in Post-Recession Rural American, Brief No. 01-16.

[58] Karlan, Dean, Margaret McConnell, Sendhil Mullainathan, and Jonathan Zinman. 2016. "Getting to the Top of Mind: How Reminders Increase Saving." Management Science, 62(12): 3393-3411.

[59] Kochhar, Rakesh, Richard Fry, and Paul Taylor. 2011. "Wealth Gaps Rise to Record Highs between Whites, Blacks and Hispanics." Pew Research Center Report, http://www.pewsocialtrends.org/2011/07/26/wealth-gaps-rise-to-record-highs-betweenwhites-blacks-hispanics/.

[60] Lauffer, Sarah. 2017. "Characteristics of Supplemental Nutrition Assistance Program Households: Fiscal Year 2016." Washington, DC: United States Department of Agriculture, Food and Nutrition Service.

[61] Madrian, Brigitte C., and Dennis F. Shea. 2001. "The Power of Suggestion: Inertia in 401(k) Participation and Savings Behavior." Quarterly Journal of Economics, 116(4): 1149-1187.

[62] McCrary, Justin. 2007. "The Effect of Court-Ordered Hiring Quotas on the Composition and Quality of Police." American Economic Review, 97(1): 318-353.

[63] McKernan, Signe-Mary, Caroline Ratcliffe, C. Eugene Steuerle, and Sisi Zhang. 2014. "Impact of the Great Recession and Beyond: Disparities in Wealth Building by Generation and Race." Urban Institute Report, https://www.urban.org/research/publication/impact-greatrecession-and-beyond.

[64] Meyer, Bruce D., Nikolas Mittag, and Robert M. Goerge. 2018. "Errors in Survey Reporting and Imputation and their Effects on Estimates of Food Stamp Program Participation." NBER Working Paper, 25143.

[65] Moffitt, Robert. 1983. "An Economic Model of Welfare Stigma." American Economic Review, 73(5): 1023-1035.

[66] Morin, Rich, Paul Taylor, and Eileen Patten. 2012. "A Bipartisan Nation of Beneficiaries." Pew Research Center Report. http://www.pewsocialtrends.org/2012/12/18/a-bipartisannation-of-beneficiaries/.

[67] Nord, Mark, Margaret Andrews, and Steven Carlson. 2006. "Household Food Security in the United States, 2005." Economic Research Report Number 29. Washington, DC: United States Department of Agriculture, Economic Research Service. 
[68] O'Hare, William P. 2018. "Citizenship Question Nonresponse: A Demographic Profile of People Who Do Not Answer the American Community Survey Citizenship Question." Georgetown Law Center on Poverty and Inequality Report.

[69] Panel Study of Income Dynamics. 2000. "Information on the PSID Immigrant Sample Addition of 1997/1999." Technical Series Paper 00-04.

[70] Panel Study of Income Dynamics, public use dataset and restricted use data, county level identifiers. Produced and distributed by the Survey Research Center, Institute for Social Research, University of Michigan, Ann Arbor, MI, 2017.

[71] Passel, Jeffrey S., and D'vera Cohn. 2018. "U.S. Unauthorized Immigrant Total Dips to Lowest Level in a Decade." http://www.pewhispanic.org/2018/11/27/u-s-unauthorized-immigranttotal-dips-to-lowest-level-in-a-decade/. Washington D.C.: Pew Research Center.

[72] Pedraza, Francisco I., and Ling Zhu. 2014. "Immigration Enforcement and the Chilling Effect on Latino Medicaid Enrollment." Working Paper.

[73] Pedraza, Francisco I., and Maricruz Ariana Osorio. 2017. "Courted and Deported: The Salience of Immigration Issues and Avoidance of Police, Health Care, and Education Services among Latinos." Aztlán: A Journal of Chicano Studies, 42(2): 247-264.

[74] Perreira, Krista M., Hirokazu Yoshikawa, and Jonathan Oberlander. 2018. "A New Threat to Immigrants' Health - The Public-Charge Rule." The New England Journal of Medicine, 379: 901-903.

[75] Rubin, Donald B. 1974. "Estimating Causal Effects of Treatments in Randomized and Nonrandomized Studies." Educational Psychology, 66(5): 688-701.

[76] Ruggles, Steven, Sarah Flood, Ronald Goeken, Josiah Grover, Erin Meyer, Jose Pacas and Matthew Sobek. 2019. IPUMS USA: Version 9.0 [2006-2016]. Minneapolis, MN: IPUMS 2019.

[77] Sampson, Robert J., and Janet L. Lauritsen. 1997. "Racial and Ethnic Disparities in Crime and Criminal Justice in the United States." Crime and Justice, 21: 311-374.

[78] Schmidt, Lucie, Lara Shore-Sheppard, and Tara Watson. 2016. "The Effect of Safety-Net Programs on Food Insecurity." Journal of Human Resources, 51(3): 589-614.

[79] Short, Kathleen. 2014. "The Research Supplemental Poverty Measure: 2013." Current Population Reports P60-251. US Census Bureau.

[80] Slemrod, Joel. 1990. "Fear of Nuclear War and Intercountry Differences in the Rate of Saving." Economic Inquiry, 28(4): 647-657.

[81] Solon, Gary, Steven J. Haider, and Jeffrey M. Wooldridge. 2015. "What Are We Weighting For?" Journal of Human Resources, 50(2): 301-316.

[82] Tiehen, Laura, Dean Jolliffe, and Craig Gundersen. 2012. "Alleviating Poverty in the United States: The Critical Role of SNAP Benefits." Economic Research Report 132. Washington, DC: United States Department of Agriculture, Economic Research Service.

[83] TRACFED 2016. "TRACFED: A Unique Source of Authoritative Information about the Federal Government's Enforcement Activity." Syracuse, N.Y.: Transactional Records Access Clearinghouse, Syracuse University.

[84] Tyler, Tom. 2006. Why People Obey the Law. Princeton, NJ: Princeton University Press. 
[85] United States Immigration and Customs Enforcement. 2011. "Secure Communities: Quarterly Report Fiscal Year 2010 Report to Congress, Fourth Quarter." Washington D.C.: United States Immigration and Customs Enforcement.

[86] United States Immigration and Customs Enforcement. 2015. "ICE's Use of IDENT/IAFIS Interoperability. Monthly Statistics through February 28, 2015." Washington D.C.: United States Immigration and Customs Enforcement.

[87] United States Immigration and Customs Enforcement. 2017. "Declined Detainer Outcome Report." https://www.ice.gov/doclib/ddor/ddor2017_02-04to02-10.pdf Washington D.C.: United States Immigration and Customs Enforcement.

[88] United States Social Security Administration. 2013. "SSI Annual Statistical Report, 2012." Washington D.C.: United States Social Security Administration.

[89] Vargas, Edward D., and Maureen A. Pirog. 2016. "Mixed-Status Families and WIC Uptake: The Effects of Risk of Deportation on Program Use." Social Science Quarterly, 97(3): 555-572.

[90] Vargas, Edward D., and Vickie D. Ybarra. 2017. "U.S. Citizen Children of Undocumented Parents: The Link between State Immigration Policy and the Health of Latino Children." Journal of Immigrant and Minority Health, 19(4): 913-920.

[91] Watson, Tara. 2014. "Inside the Refrigerator: Immigration Enforcement and Chilling in Immigrant Medicaid Participation." American Economic Journal: Economic Policy, 6: 313-338.

[92] Wolkwitz, Kari. 2007. "Characteristics of Food Stamp Households: Fiscal Year 2006." Report No. FSP-07-CHAR. Washington, DC: United States Department of Agriculture, Food and Nutrition Service.

[93] Yoshikawa, Hirokazu. 2011. Immigrants Raising Citizens: Undocumented Parents and Their Young Children. New York, NY: Russell Sage Foundation. 
Table 1: Balance Table

ACS Citizens Sample (2006-2008)

\begin{tabular}{lcc}
\hline & $\begin{array}{c}\text { F-Statistic } \\
(1)\end{array}$ & $\begin{array}{c}\text { p-value } \\
(2)\end{array}$ \\
\cline { 2 - 3 } Outcome & & \\
Log Poverty & 2.141 & 0.073 \\
\# Children & 0.932 & 0.444 \\
Share Employed & 1.104 & 0.399 \\
Share Citizen & 2.980 & 0.018 \\
Share Food Stamp & 1.715 & 0.144 \\
Share SSI & 2.415 & 0.047 \\
& & \\
$\Delta$ Log Poverty & 0.668 & 0.615 \\
$\Delta$ \# Children & 2.477 & 0.043 \\
$\Delta$ Share Employed & 1.599 & 0.172 \\
$\Delta$ Share Citizen & 2.326 & 0.055 \\
$\Delta$ Share Food Stamp & 1.505 & 0.198 \\
$\Delta$ Share SSI & 1.508 & 0.197 \\
\hline
\end{tabular}

Note: Data from ACS 2006-2008. The data are limited to heads of households with less than a high school degree that are U.S. citizens, defined as individuals born in the United States or those who are naturalized and have lived in the United States for at least a decade. This table presents results from a regression of the mean Hispanic-white difference for each outcome variable on fixed effects for each activation year group. All regressions control for state fixed effects, log crime, and the mean black-white difference in the outcome variable. Columns 1 and 2 present Fstatistics and p-values from an F-test of the joint significance of the activation year group fixed effects. Observations in the ACS are weighted by the population in each county. Robust standard errors are clustered at the county level. 
Table 2: Triple Differences Estimation - Food Stamp and SSI Take-Up ACS Citizens Sample

\begin{tabular}{lcccc}
\hline \multirow{1}{*}{ Outcome } & \multicolumn{2}{c}{ Share Food Stamp } & \multicolumn{2}{c}{ Share SSI } \\
& $(1)$ & $(2)$ & $(3)$ & $(4)$ \\
\cline { 2 - 5 } Hispanic $\times$ Post & $-0.021^{* * *}$ & $-0.022^{* *}$ & $-0.016^{* * *}$ & $-0.017^{* * *}$ \\
& $(0.008)$ & $(0.009)$ & $(0.006)$ & $(0.006)$ \\
Post & 0.005 & 0.005 & $0.006^{* *}$ & $0.007^{* *}$ \\
& $(0.004)$ & $(0.004)$ & $(0.003)$ & $(0.003)$ \\
Black $\times$ Post & & -0.003 & & -0.005 \\
& & $(0.009)$ & & $(0.006)$ \\
Pre-Period Hisp. Mean & 0.218 & 0.218 & 0.053 & 0.053 \\
Fixed Effects & State-Yr, State-Race, Race-Yr, County-Morton \\
Baseline Controls & Yes & Yes & Yes & Yes \\
Observations & 80,977 & 80,977 & 80,977 & 80,977 \\
Number Clusters & 2,759 & 2,759 & 2,759 & 2,759 \\
\hline
\end{tabular}

Note: Data from ACS 2006-2016. The data are limited to heads of households with less than a high school degree that are U.S. citizens, defined as individuals born in the United States or those who are naturalized and have lived in the United States for at least a decade. Baseline controls in the ACS include log poverty, number of children, share employed, share citizen, and FBI log crime interacted with race. All regressions control for county-by-Morton memo fixed effects, state-by-year fixed effects, state-by-race fixed effects, race-by-year fixed effects, and race-by-state changes in employment during the Great Recession. Observations in the ACS are weighted by the race-specific population in each county. Robust standard errors clustered at the county level are reported in parentheses. $* * *=$ significant at 1 percent level, ${ }^{* *}=$ significant at 5 percent level, ${ }^{*}=$ significant at 10 percent level. 
Table 3: Triple Differences Estimation - Food Stamp and SSI Take-Up PSID Citizens Sample

\begin{tabular}{lcccc}
\hline \multirow{1}{*}{ Outcome } & \multicolumn{2}{c}{ Share Food Stamp } & \multicolumn{2}{c}{ Share SSI } \\
& Sll & Prior User & All & Prior User \\
& $(1)$ & $(2)$ & $(3)$ & $(4)$ \\
\cline { 2 - 5 } Hispanic $\times$ Post & -0.138 & $-0.496^{* * *}$ & -0.019 & $-1.129^{* *}$ \\
& $(0.112)$ & $(0.206)$ & $(0.078)$ & $(0.525)$ \\
Post & 0.060 & 0.058 & 0.064 & 0.029 \\
& $(0.054)$ & $(0.096)$ & $(0.049)$ & $(0.164)$ \\
Pre-Period Hisp. Mean & 0.341 & 0.728 & 0.040 & 0.493 \\
Fixed Effects & State-Yr, State-Race, Race-Yr, County-Morton \\
Baseline Controls & Yes & Yes & Yes & Yes \\
Observations & 19,596 & 10,643 & 18,051 & 3,156 \\
Number Clusters & 628 & 369 & 610 & 178 \\
\hline
\end{tabular}

Note: Data from PSID 2005-2015. The data are limited to individuals from families where the heads of household have less than a high school degree and grew up in the United States or were born to parents who were born in the United States. Prior users in the PSID includes households that had previously taken up food stamps and/or SSI prior to SC activation. Baseline controls in the PSID include number of children, log poverty, disability-by-race-by-over 65 fixed effects, employment status, health status, sex, marital status, share citizen, and FBI log crime interacted with race. All regressions control for county-by-Morton memo fixed effects, state-by-year fixed effects, state-by-race fixed effects, race-by-year fixed effects, and race-by-state changes in employment during the Great Recession. Observations in the PSID are weighted by the PSID family weight. Robust standard errors clustered at the county level are reported in parentheses. ${ }^{* * *}=$ significant at 1 percent level, $* *=$ significant at 5 percent level, ${ }^{*}=$ significant at 10 percent level. 
Table 4: Robustness Checks

ACS Citizens Sample

\begin{tabular}{|c|c|c|c|c|c|c|}
\hline & $\begin{array}{l}\text { No } G R \\
\quad(1)\end{array}$ & $\begin{array}{c}\text { County- } Y r F E \\
(2)\end{array}$ & $\begin{array}{c}\text { Predicted } Y r \\
\text { (3) }\end{array}$ & $\begin{array}{c}\text { Hisp } / \text { Nonhisp } \\
\text { (4) }\end{array}$ & $\begin{array}{c}\text { Freyaldenhoven } \\
(5)\end{array}$ & $\begin{array}{c}<\text { College } \\
(6)\end{array}$ \\
\hline $\begin{array}{l}\text { Hispanic } \times \text { Post } \\
\text { Post }\end{array}$ & $\begin{array}{c}-0.021^{* * *} \\
(0.008) \\
0.005 \\
(0.004)\end{array}$ & $\begin{array}{r}\mathrm{Pa} \\
-0.020^{\text {** }} \\
(0.009)\end{array}$ & $\begin{array}{c}\text { A: Share Fc } \\
-0.016^{*} \\
(0.009) \\
-0.007^{*} \\
(0.004) \\
\end{array}$ & $\begin{array}{c}\mathrm{d} \text { Stamp } \\
-0.025^{* * *} \\
(0.008) \\
0.010^{* *} \\
(0.004)\end{array}$ & $\begin{array}{c}-0.019^{* *} \\
(0.008) \\
0.001 \\
(0.002) \\
\end{array}$ & $\begin{array}{c}-0.007^{*} \\
(0.004) \\
-0.001 \\
(0.001) \\
\end{array}$ \\
\hline $\begin{array}{l}\text { Hispanic } \times \text { Post } \\
\text { Post }\end{array}$ & $\begin{array}{c}-0.016^{* * *} \\
(0.006) \\
0.006^{* *} \\
(0.003)\end{array}$ & $\begin{array}{c}-0.017^{* *} \\
(0.007)\end{array}$ & $\begin{array}{c}\text { Panel B: Shat } \\
-0.015^{* *} \\
(0.006) \\
0.004 \\
(0.003)\end{array}$ & $\begin{array}{c}-0.018^{* * *} \\
(0.005) \\
0.008^{* * *} \\
(0.003)\end{array}$ & $\begin{array}{c}-0.017^{* *} \\
(0.007) \\
0.003 \\
(0.002)\end{array}$ & $\begin{array}{c}-0.003 \\
(0.002) \\
0.0001 \\
(0.001)\end{array}$ \\
\hline $\begin{array}{l}\text { Fixed Effects } \\
\text { Baseline Controls } \\
\text { Observations }\end{array}$ & $\begin{array}{c}\text { Yes } \\
80,977\end{array}$ & $\begin{array}{c}\text { State- } \\
\text { Yes } \\
79,946\end{array}$ & $\begin{array}{c}\text { r, State-Race } \\
\text { Yes } \\
80,977\end{array}$ & $\begin{array}{c}\text { Race-Yr, County } \\
\text { Yes } \\
56,312\end{array}$ & $\begin{array}{r}\text {-Morton } \\
\text { Yes } \\
71,660\end{array}$ & $\begin{array}{c}\text { Yes } \\
89,671\end{array}$ \\
\hline
\end{tabular}

Note: Data from ACS 2006-2016. The data are limited to heads of households with less than a high school degree that are U.S. citizens, defined as individuals born in the United States or those who are naturalized and have lived in the United States for at least a decade. Baseline controls in the ACS include log poverty, number of children, share employed, share citizen, and FBI log crime interacted with race. All regressions control for county-by-Morton memo fixed effects, state-by-year fixed effects, state-by-race fixed effects, and race-by-year fixed effects. Observations in the ACS are weighted by the race-specific population in each county. Column 1 estimates our main specification excluding race-by-state changes in employment during the Great Recession. Column 2 replaces county-by-Morton memo fixed effects with county-by-year fixed effects to our main specification. Column 3 estimates our main specification using predicted activation date instead of actual activation. Column 4 estimates our main specification comparing Hispanics to all non-Hispanics. Column 5 estimates our main specification instrumenting for pre-SC activation trends in program take-up following Freyaldenhoven, Hansen, and Shapiro (forthcoming). Column 6 estimates our main specification on a sample of household heads with less than a college degree. Robust standard errors clustered at the county level are reported in parentheses. ${ }^{* * *}=$ significant at 1 percent level, $* *=$ significant at 5 percent level, $*=$ significant at 10 percent level. 
Table 5: Food Stamp and SSI Take-Up Heterogeneity ACS Citizens Sample

\begin{tabular}{|c|c|c|c|c|c|c|c|c|}
\hline \multirow[t]{2}{*}{ Outcome } & \multicolumn{4}{|c|}{ Share Food Stamp } & \multicolumn{4}{|c|}{ Share SSI } \\
\hline & $(1)$ & (2) & $(3)$ & $(4)$ & $(5)$ & $(6)$ & (7) & $(8)$ \\
\hline Hispanic $\times$ Post & $\begin{array}{c}0.007 \\
(0.015)\end{array}$ & $\begin{array}{c}-0.043^{* * *} \\
(0.009)\end{array}$ & $\begin{array}{c}-0.025^{* * *} \\
(0.008)\end{array}$ & $\begin{array}{c}-0.029^{* * *} \\
(0.008)\end{array}$ & $\begin{array}{r}-0.003 \\
(0.012)\end{array}$ & $\begin{array}{c}-0.025^{* * *} \\
(0.006)\end{array}$ & $\begin{array}{c}-0.015^{\text {*** }} \\
(0.006)\end{array}$ & $\begin{array}{c}-0.023^{* * *} \\
(0.006)\end{array}$ \\
\hline Hispanic $\times$ Post $\times$ Proportion Petty & $\begin{array}{c}-0.057^{* *} \\
(0.025)\end{array}$ & & & & $\begin{array}{r}-0.026 \\
(0.016)\end{array}$ & & & \\
\hline Hispanic $\times$ Post $\times \Delta$ Pew Fear & & $\begin{array}{c}-0.213^{* * *} \\
(0.050)\end{array}$ & & & & $\begin{array}{c}-0.101^{* * *} \\
(0.030)\end{array}$ & & \\
\hline Hispanic $\times$ Post $\times$ Sanctuary City & & & $\begin{array}{l}0.036^{\text {*** }} \\
(0.010)\end{array}$ & & & & $\begin{array}{r}-0.006 \\
(0.007)\end{array}$ & \\
\hline Hispanic $\times$ Post $\times \% \mathrm{PR} /$ Cuban & & & & $\begin{array}{c}0.032^{* *} \\
(0.013)\end{array}$ & & & & $\begin{array}{l}0.041^{\text {*** }} \\
(0.008)\end{array}$ \\
\hline Fixed Effects & & & State-Yr, S & ate-Race, $\mathrm{P}$ & ace-Yr, $\mathrm{Cc}$ & aty-Morton & & \\
\hline Baseline Controls & Yes & Yes & Yes & Yes & Yes & Yes & Yes & Yes \\
\hline Observations & 65,903 & 76,800 & 86,407 & 77,465 & 65,903 & 76,800 & 86,407 & 77,465 \\
\hline
\end{tabular}

Note: Data from ACS 2006-2016. The data are limited to heads of households with less than a high school degree that are U.S. citizens, defined as individuals born in the United States or those who are naturalized and have lived in the United States for at least a decade. Proportion Petty measures the share of Hispanic detainers issued for minor offenses relative to those for both minor and serious offenses. $\Delta$ Pew Fear measures the change in the share that are worried a family member or close friend could be deported between 2013 and 2010 from Pew. This measure is defined at the Census division level. Sanctuary city is an indicator for an active sanctuary city policy during the period of SC activation. \% PR/Cuban measures the share of Hispanic households with a Puerto Rican or Cuban head in a county. All specifications contain main terms and the full set of interactions with the Hispanic indicator, black indicator and post-SC indicator. Baseline controls in the ACS include log poverty, number of children, share employed, share citizen, and FBI log crime interacted with race. All regressions control for county-by-Morton memo fixed effects, state-by-year fixed effects, state-by-race fixed effects, race-by-year fixed effects, and race-by-state changes in employment during the Great Recession. Observations in the ACS are weighted by the race-specific population in each county. Robust standard errors clustered at the county level are reported in parentheses. $* * *=$ significant at 1 percent level, ${ }^{* *}=$ significant at 5 percent level, ${ }^{*}=$ significant at 10 percent level. 
Table 6: Compositional Changes

ACS Citizens Sample

\begin{tabular}{|c|c|c|c|c|c|c|c|}
\hline Outcome & $\begin{array}{c}\text { \# Child } \\
\text { (1) }\end{array}$ & $\begin{array}{c}\text { Log Pov } \\
(2)\end{array}$ & $\begin{array}{c}\% \underset{(3)}{E m p} \\
\text { (3) }\end{array}$ & $\begin{array}{c}\% \text { Moved } \\
\text { (4) }\end{array}$ & $\begin{array}{c}H H \\
(5)\end{array}$ & $\begin{array}{c}\% \text { Mixed } \\
(6)\end{array}$ & $\begin{array}{c}\% \text { Citizen } \\
(7)\end{array}$ \\
\hline Hispanic $\times$ Post & $\begin{array}{c}0.007 \\
(0.024)\end{array}$ & $\begin{array}{c}0.033 \\
(0.025)\end{array}$ & $\begin{array}{c}-0.002 \\
(0.002)\end{array}$ & $\begin{array}{c}0.003 \\
(0.002)\end{array}$ & $\begin{array}{c}-0.870 \\
(2.896)\end{array}$ & & \\
\hline Post & $\begin{array}{c}0.001 \\
(0.010)\end{array}$ & $\begin{array}{r}-0.017^{*} \\
(0.009)\end{array}$ & $\begin{array}{c}0.001 \\
(0.001)\end{array}$ & $\begin{array}{c}-0.001 \\
(0.001)\end{array}$ & $\begin{array}{c}-2.206 \\
(2.192)\end{array}$ & $\begin{array}{c}0.008 \\
(0.008)\end{array}$ & $\begin{array}{c}0.003^{*} \\
(0.002)\end{array}$ \\
\hline Pre-Period Hisp. Mean & 0.713 & 3.766 & 0.377 & 0.054 & 107.620 & 0.176 & 0.687 \\
\hline Fixed Effects & \multicolumn{7}{|c|}{ State-Yr, State-Race, Race-Yr, County-Morton } \\
\hline Baseline Controls & Yes & Yes & Yes & Yes & Yes & Yes & Yes \\
\hline Observations & 80,977 & 80,977 & 80,977 & 80,977 & 80,977 & 25,342 & 25,342 \\
\hline
\end{tabular}

Note: Data from ACS 2006-2016. The data are limited to heads of households with less than a high school degree that are U.S. citizens, defined as individuals born in the United States or those who are naturalized and have lived in the United States for at least a decade. Baseline controls include FBI log crime interacted with race and, in column 1 log poverty, share employed, and share citizen, in column 2 number of children, share employed, and share citizen, in column 3 number of children, log poverty, and share citizen, and in columns 4-7 log poverty, number of children, share employed, and share citizen. All regressions control for county-by-Morton memo fixed effects, state-by-year fixed effects, state-by-race fixed effects, race-by-year fixed effects, and race-by-state changes in employment during the Great Recession. Observations in the ACS are weighted by the race-specific population in each county. Robust standard errors clustered at the county level are reported in parentheses. ${ }^{* * *}=$ significant at 1 percent level, ${ }^{* *}=$ significant at 5 percent level, $*=$ significant at 10 percent level. 
Figure 1: Detainers by Year

Panel A: Total by Year

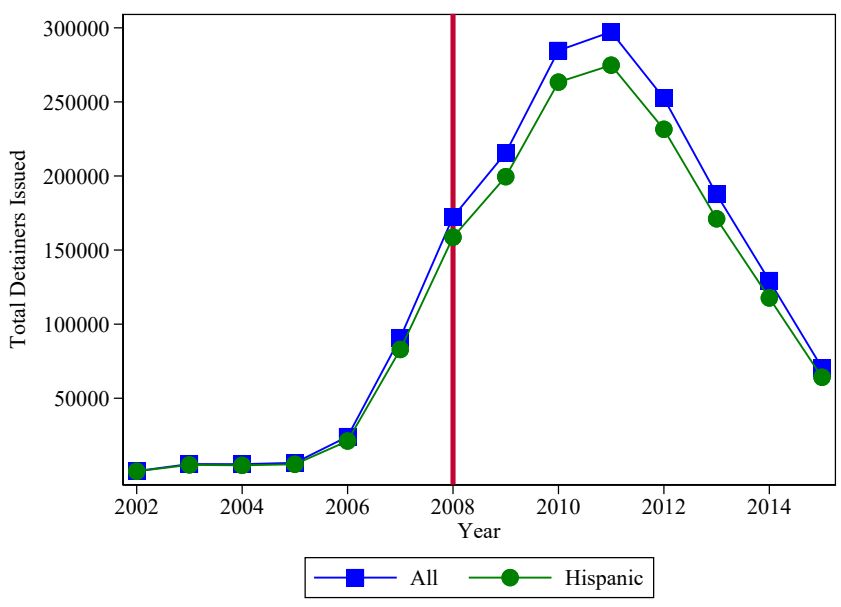

Panel B: Cumulative by Year

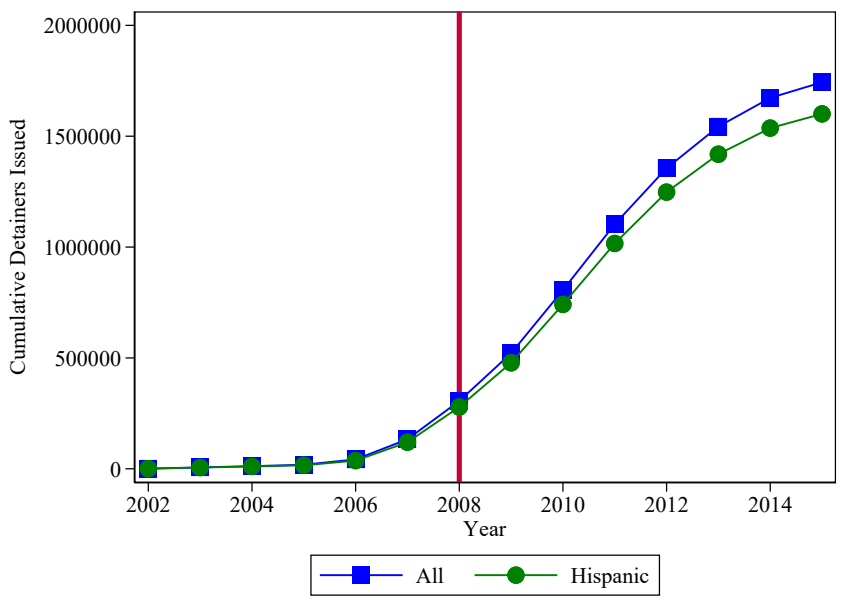

Panel C: Ratio of Low-Level to Violent Offenses

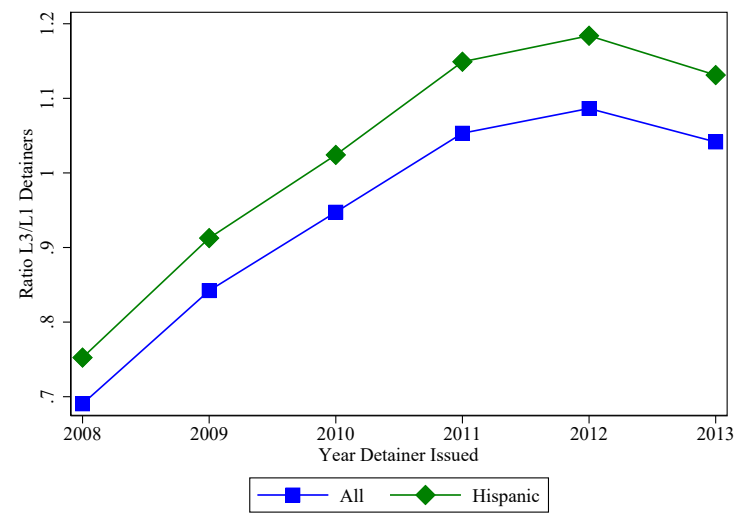

Note: Data from TRACFED (2016). 
Figure 2: Secure Communities Activation
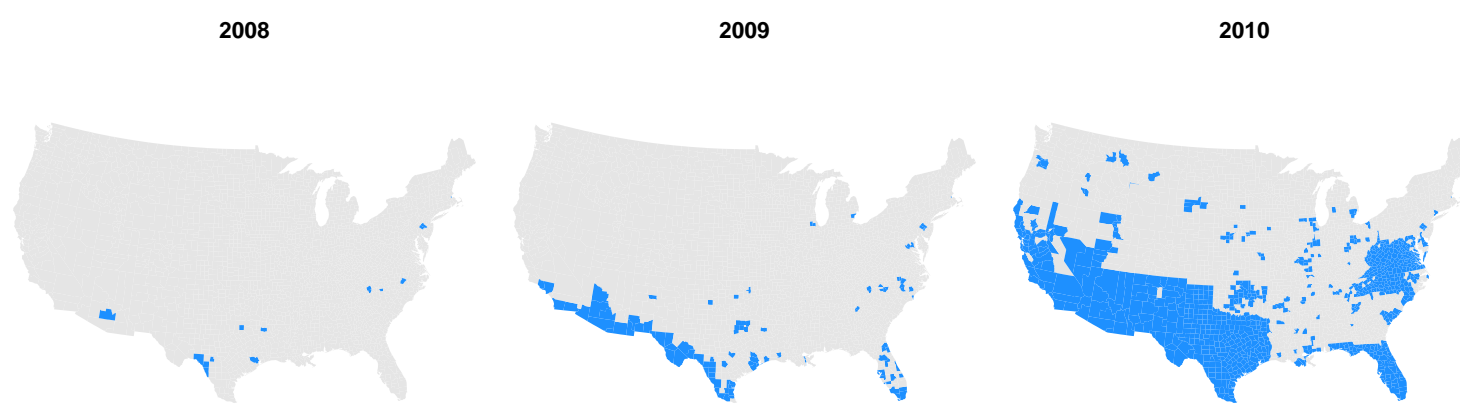

2011

2012

2013
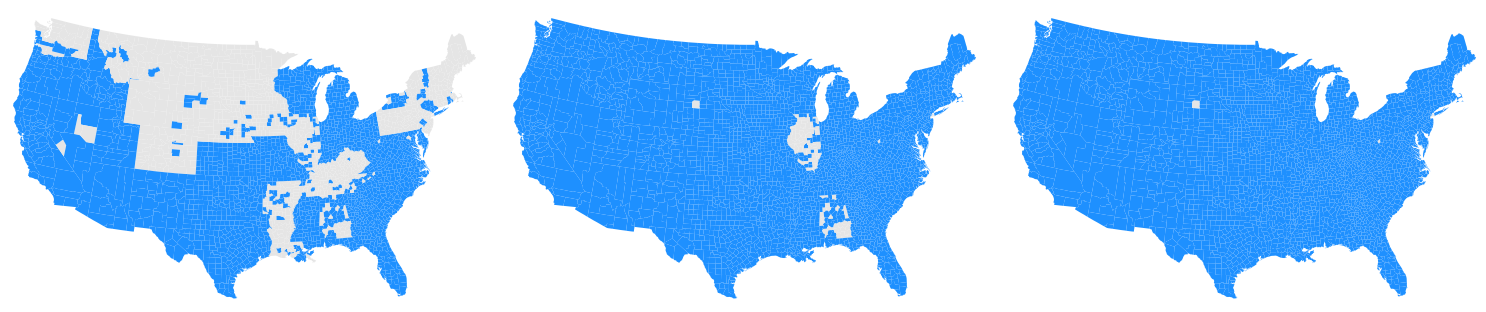

Note: Data from US ICE (2015). 
Figure 3: Predicted Secure Communities Activation
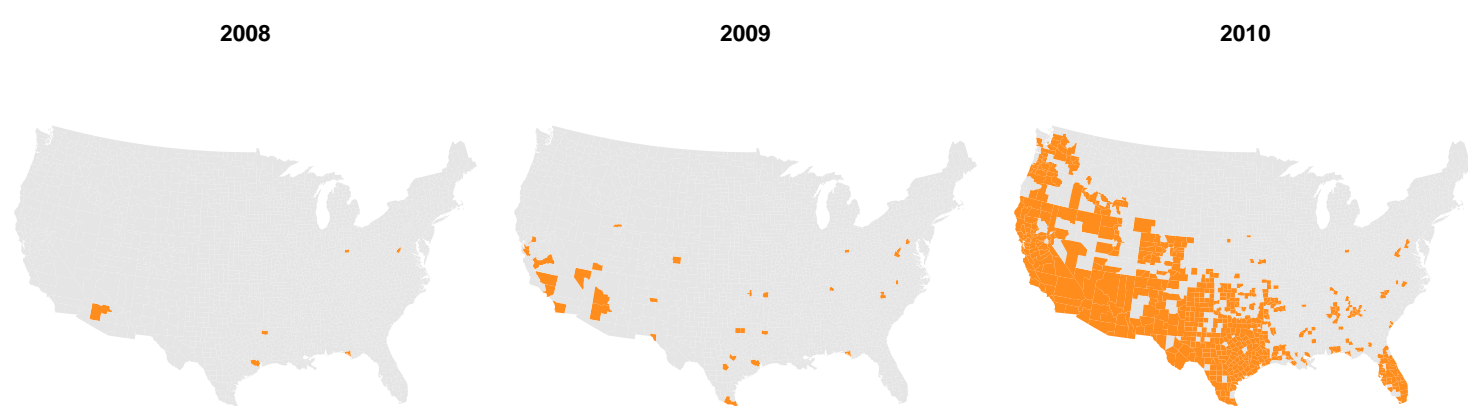

2011

2012
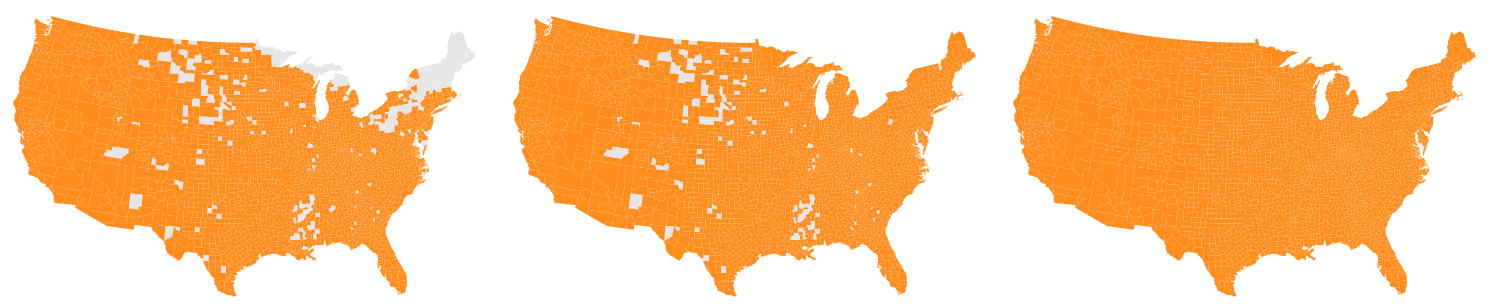

Note: Predicted values based on information from ICE Quarterly Reports (US ICE 2011). See text for details of prediction. 
Figure 4: Event Study of Food Stamp and SSI Take-Up

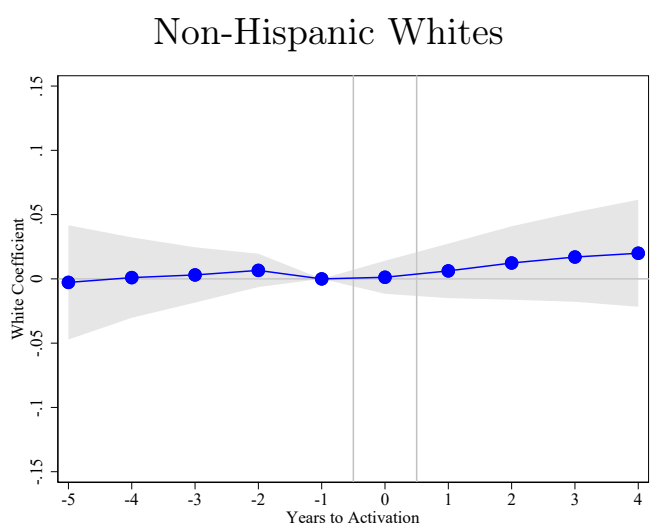

Panel A. Share Food Stamp

Non-Hispanic Blacks

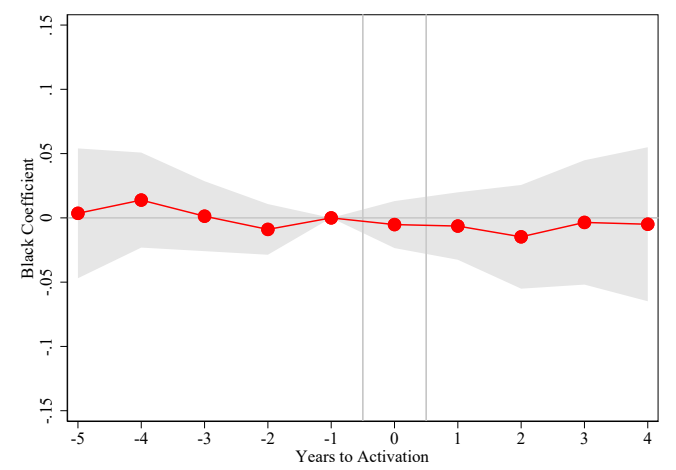

Panel B. Share SSI

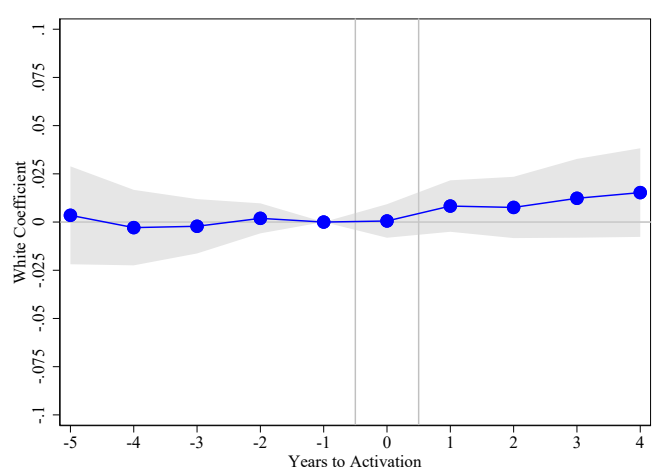

Non-Hispanic Blacks

Non-Hispanic Whites

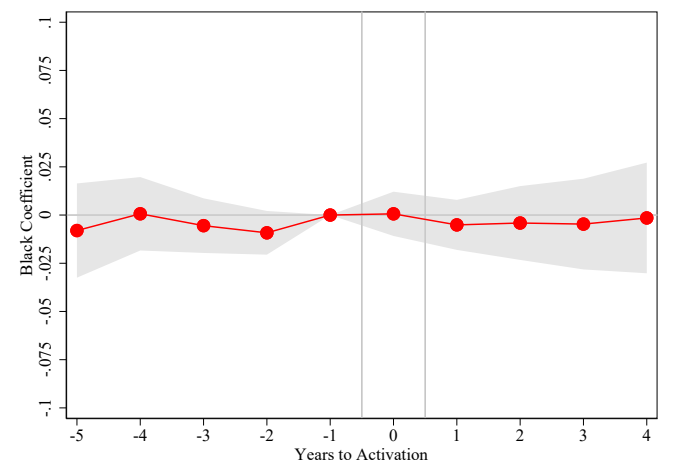

Hispanics

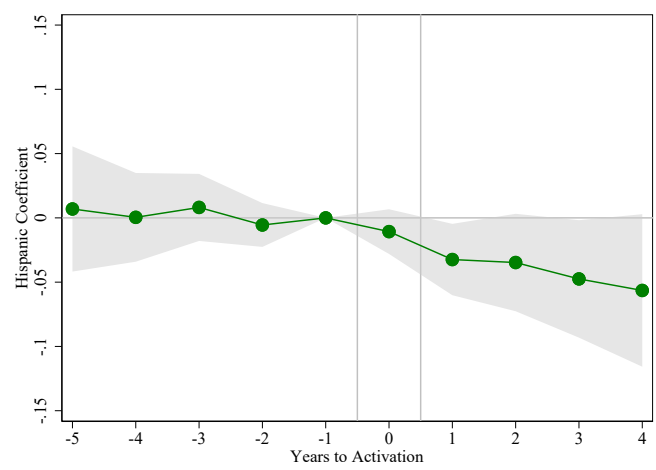

Hispanics

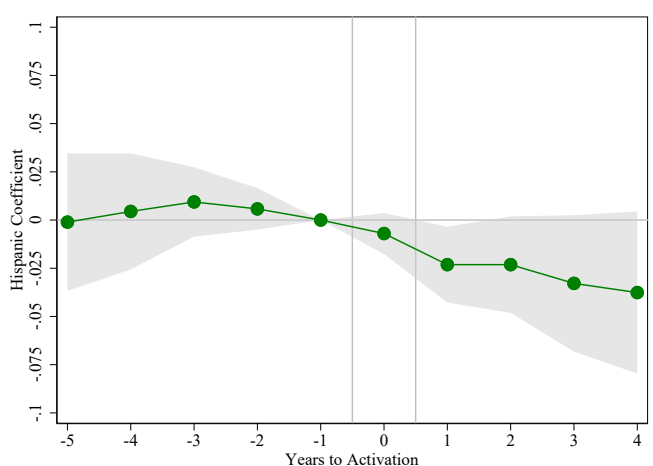

Note: Data from ACS from 2006-2016. Coefficients and 95\% confidence intervals are plotted. The data are limited to heads of households with less than a high school degree that are U.S. citizens, defined as individuals born in the United States or those who are naturalized and have lived in the United States for at least a decade. Baseline controls in the ACS include log poverty, number of children, share employed, share citizen, and FBI log crime interacted with race. All regressions control for county-by-Morton memo fixed effects, state-by-year fixed effects, state-by-race fixed effects, race-by-year fixed effects, and race-by-state changes in employment during the Great Recession. Observations in the ACS are weighted by the race-specific population in each county. Robust standard errors are clustered at the county level. The vertical lines denote the interval of Secure Communities activation. 
Figure 5: Robustness Event Study of Food Stamp and SSI Take-Up

Non-Hispanic vs. Hispanic

Panel A: Share Food Stamp

Non-Hispanics

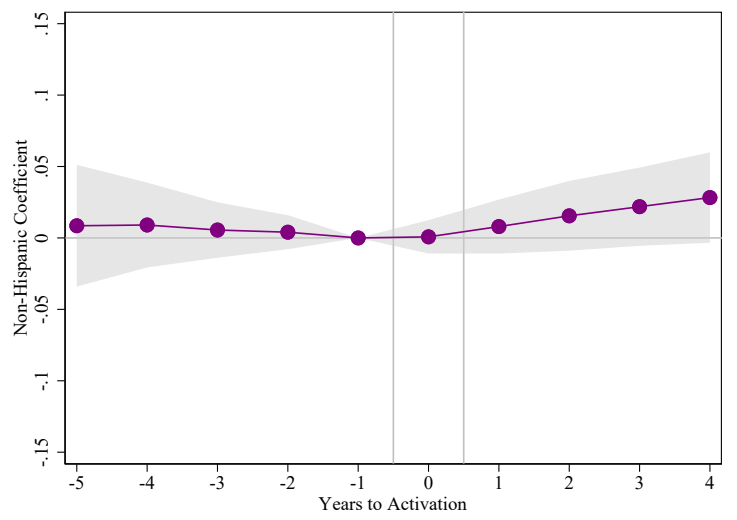

Hispanics

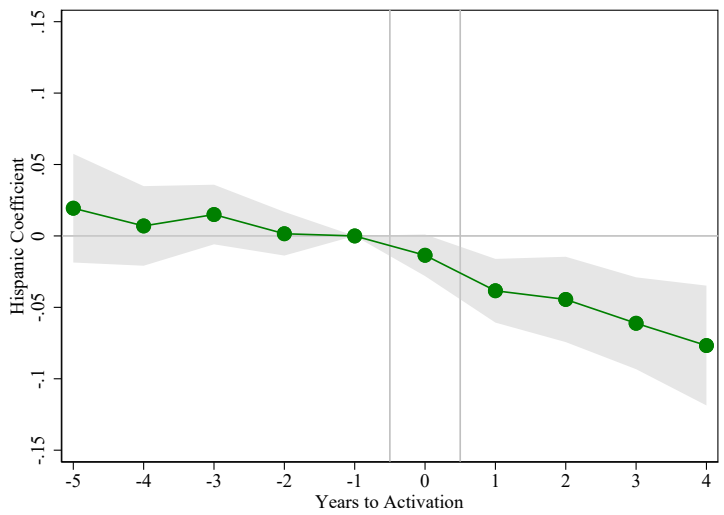

Panel B: Share SSI

Non-Hispanics

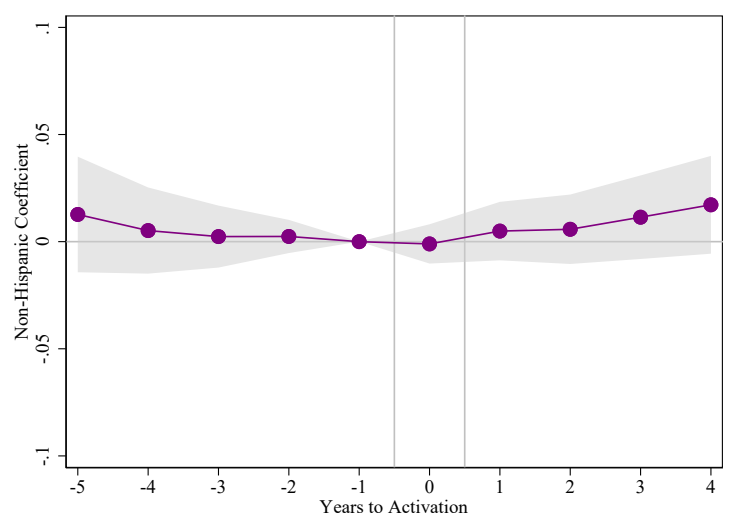

Hispanics

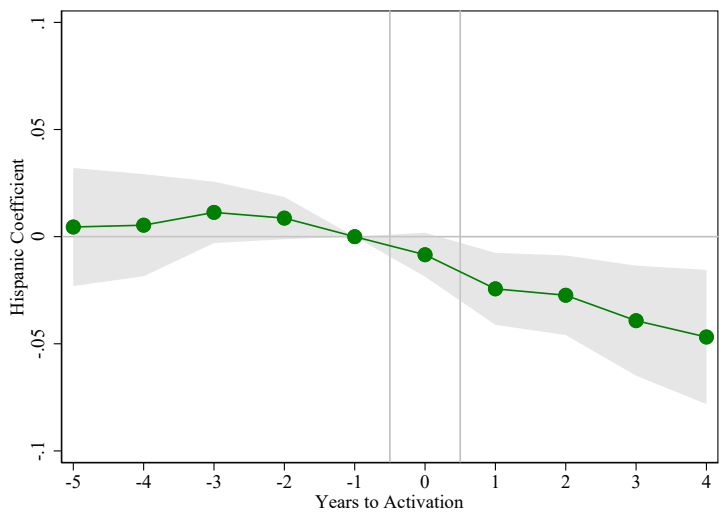

Note: Data from ACS from 2006-2016. Coefficients and 95\% confidence intervals are plotted. The data are limited to heads of households with less than a high school degree that are U.S. citizens, defined as individuals born in the United States or those who are naturalized and have lived in the United States for at least a decade. Non-Hispanic includes household heads who identify as non-Hispanic black or non-Hispanic white. Baseline controls in the ACS include log poverty, number of children, share employed, share citizen, and FBI log crime interacted with race. All regressions control for county-by-Morton memo fixed effects, state-by-year fixed effects, state-by-race fixed effects, race-by-year fixed effects, and race-by-state changes in employment during the Great Recession. Observations in the ACS are weighted by the race-specific population in each county. Robust standard errors are clustered at the county level. The vertical lines denote the interval of Secure Communities activation. 
Figure 6: Correlation between Fear and Knowing Someone Detained

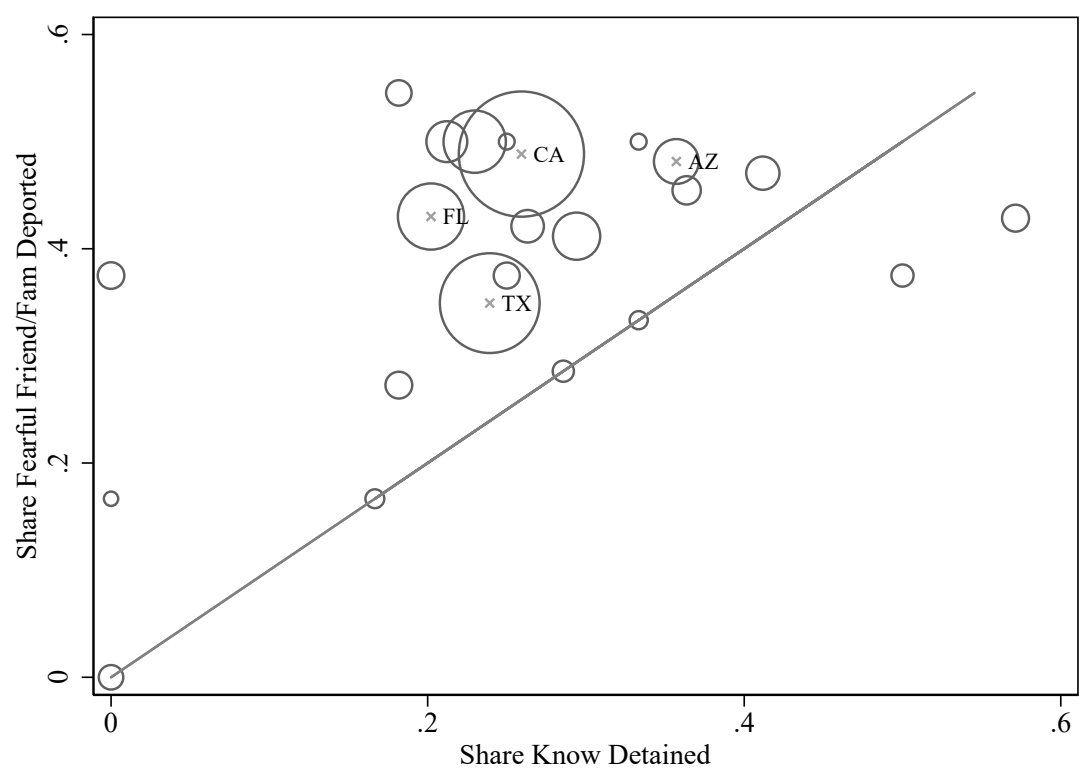

Note: Data from Pew Hispanic Survey 2010. The sample excludes non-citizens and states with five or fewer respondents. Fear refers to fear that a family member or close contact will be deported. The knowledge measure refers to the share of people responding affirmatively that they know someone who has been detained or deported. The size of the bubble represents the size of the Hispanic population. The correlation between share fear and share know detained is 0.50 . The $45^{\circ}$ line is drawn for reference. 
Figure 7: Google Deportation Searches Event Study

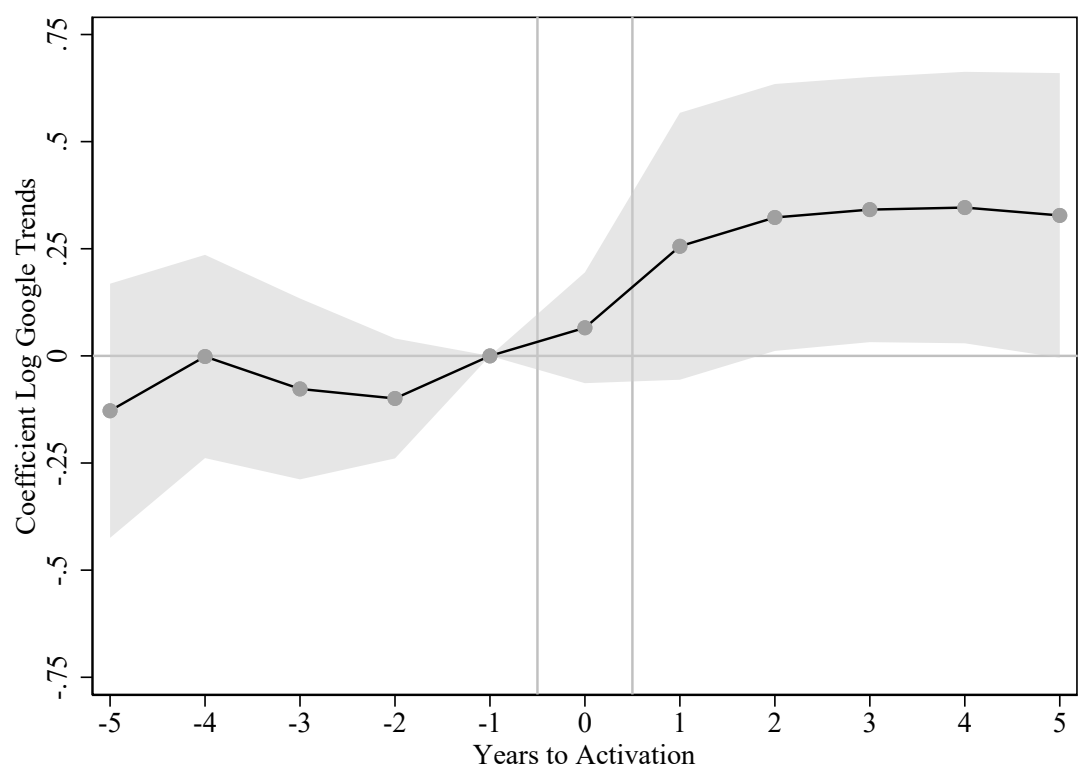

Note: Data from Google Trends. Coefficients and 95\% confidence intervals are plotted. This figure represents event study estimates of the time to SC activation on the log normalized number of deportation-related searches at the DMA media markets level. All specifications control for DMA and year fixed effects. Standard errors are clustered at the DMA level. The vertical lines denote the interval of Secure Communities activation. 
Figure 8: Intensity of Treatment and Take-Up

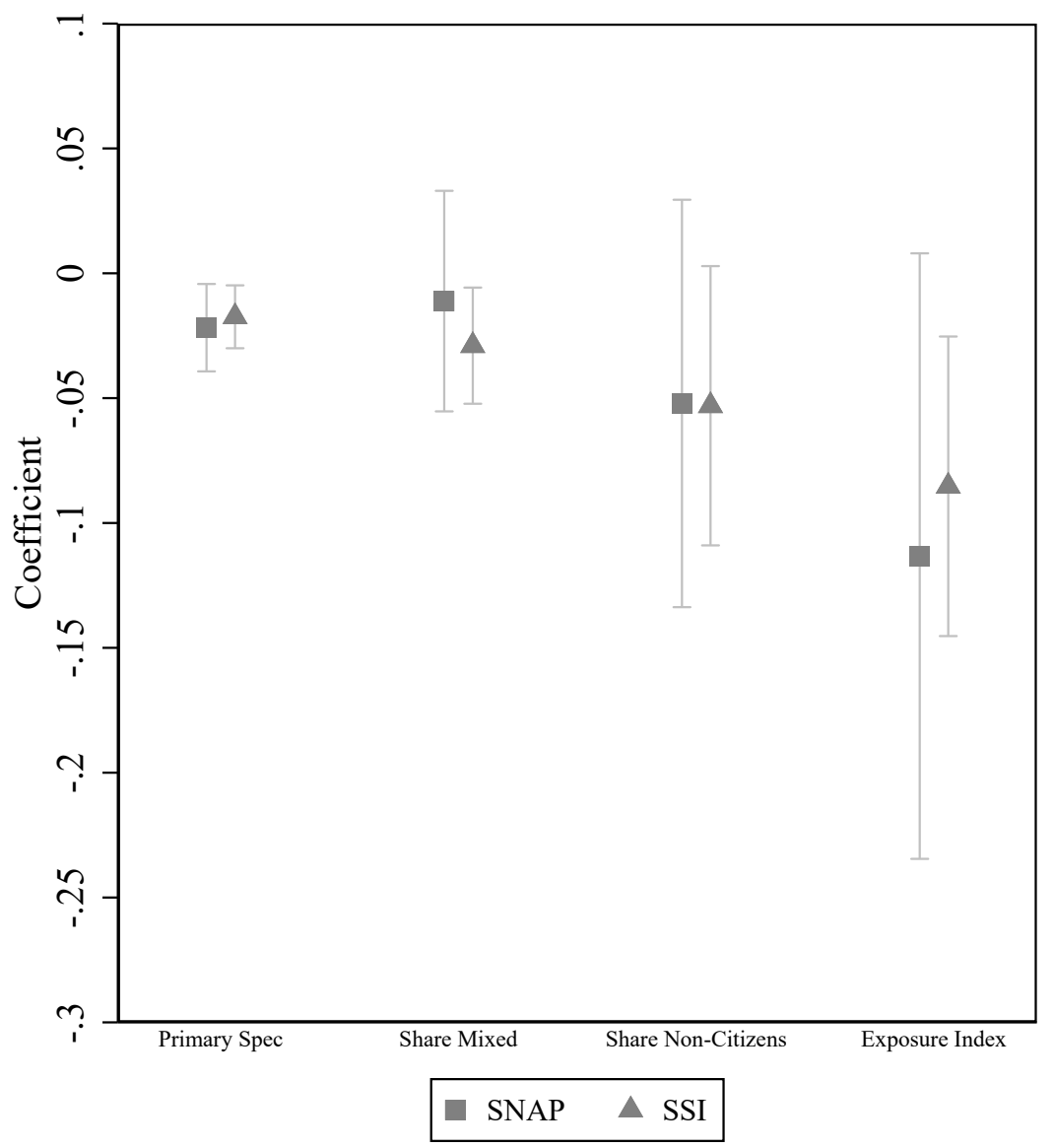

Note: Data from ACS from 2006-2016. Coefficients and 95\% confidence intervals are plotted. For "Primary Spec," we present the coefficient from Hispanic*Post in our main specification. For "Share Mixed," we present the coefficient from Hispanic*Post*\% Mixed where \% Mixed is the share of Hispanic households that are mixed-status in a county. Mixed-status family is defined as a Hispanic citizen head of household with any family member that is a Hispanic non-citizen. For "Share Non-Citizens," we present the coefficient from Hispanic*Post*\% Non-Citizen where \% NonCitizen measures the share of non-citizens among Hispanics in a county. Finally, for "Exposure Index", we present the coefficient from Hispanic*Post*Exposure Index where Exposure Index is the product of \% Mixed and \% Non-Citizen and captures the probability that a mixed-status household is randomly exposed to a Hispanic non-citizen in a county. The data are limited to heads of households with less than a high school degree that are U.S. citizens, defined as individuals born in the United States or those who are naturalized and have lived in the United States for at least a decade. Baseline controls in the ACS include log poverty, number of children, share employed, share citizen, and FBI log crime interacted with race. All regressions control for county-by-Morton memo fixed effects, state-by-year fixed effects, state-by-race fixed effects, race-by-year fixed effects, and race-by-state changes in employment during the Great Recession. Observations in the ACS are weighted by the race-specific population in each county. Robust standard errors are clustered at the county level. 